\title{
BMC
}

Neuroscience
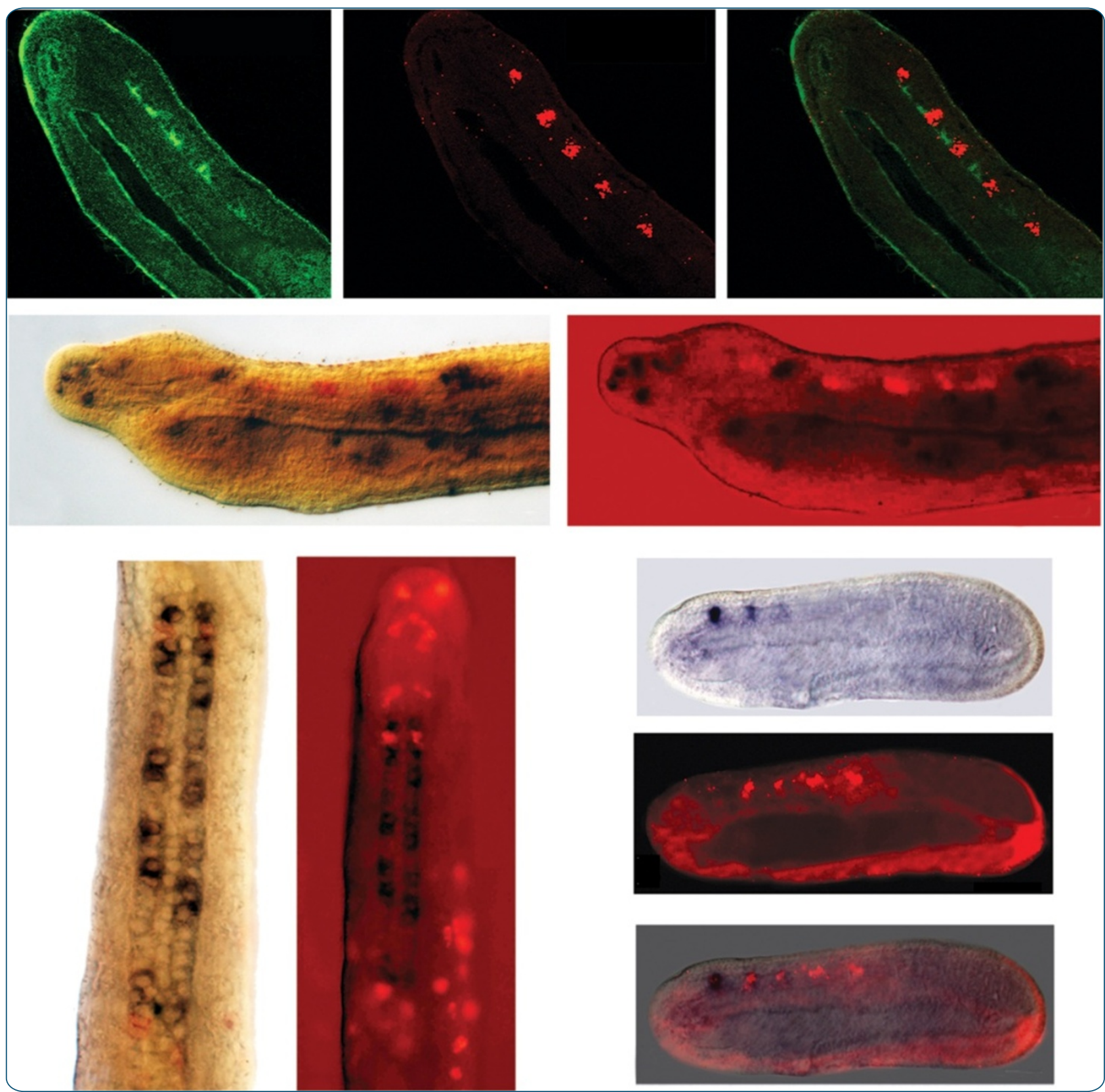

\section{A neurochemical map of the developing amphioxus nervous system}

Candiani et al.

C Biomed Central 


\title{
A neurochemical map of the developing amphioxus nervous system
}

\author{
Simona Candiani ${ }^{1 *}$, Luca Moronti ${ }^{1}$, Paola Ramoino ${ }^{1}$, Michael Schubert ${ }^{2}$ and Mario Pestarino ${ }^{1}$
}

\begin{abstract}
Background: Amphioxus, representing the most basal group of living chordates, is the best available proxy for the last invertebrate ancestor of the chordates. Although the central nervous system (CNS) of amphioxus comprises only about 20,000 neurons (as compared to billions in vertebrates), the developmental genetics and neuroanatomy of amphioxus are strikingly vertebrate-like. In the present study, we mapped the distribution of amphioxus CNS cells producing distinctive neurochemicals. To this end, we cloned genes encoding biosynthetic enzymes and/or transporters of the most common neurotransmitters and assayed their developmental expression in the embryo and early larva.

Results: By single and double in situ hybridization experiments, we identified glutamatergic, GABAergic/glycinergic, serotonergic and cholinergic neurons in developing amphioxus. In addition to characterizing the distribution of excitatory and inhibitory neurons in the developing amphioxus CNS, we observed that cholinergic and GABAergic/ glycinergic neurons are segmentally arranged in the hindbrain, whereas serotonergic, glutamatergic and dopaminergic neurons are restricted to specific regions of the cerebral vesicle and the hindbrain. We were further able to identify discrete groups of GABAergic and glutamatergic interneurons and cholinergic motoneurons at the level of the primary motor center (PMC), the major integrative center of sensory and motor stimuli of the amphioxus nerve cord.

Conclusions: In this study, we assessed neuronal differentiation in the developing amphioxus nervous system and compiled the first neurochemical map of the amphioxus CNS. This map is a first step towards a full characterization of the neurotransmitter signature of previously described nerve cell types in the amphioxus CNS, such as motoneurons and interneurons.
\end{abstract}

Keywords: Branchiostoma, Cephalochordate, Chordate evolution, Lancelet, Neural patterning, Neurotransmitter

\section{Background}

Although the genetic and developmental mechanisms of nervous system organization in vertebrates have attracted considerable attention, relatively little is known about the evolutionary origins of the vertebrate central nervous system (CNS). In all chordates, which, in addition to vertebrates, comprise the tunicates and cephalochordates (amphioxus), the anterior end of the dorsal, hollow nerve cord is enlarged to form a (at least diencephalic) forebrain, a possible midbrain and a hindbrain [1-5]. However, a definite midbrain and a midbrain-hindbrain organizer may have been vertebrate innovations $[2,6]$.

\footnotetext{
* Correspondence: candiani@unige.it

${ }^{1}$ Dipartimento per lo Studio del Territorio e delle sue Risorse, Università di Genova, Viale Benedetto XV, 5, 16132 Genoa, Italy

Full list of author information is available at the end of the article
}

Amphioxus, with its vertebrate-like body plan and unduplicated genome $[7,8]$, is a good model system to study CNS development and neuronal cell type diversity. The amphioxus CNS, which is composed of about 20,000 neurons, consists of a cerebral vesicle, a swelling at the rostral end of the nerve cord that corresponds to the vertebrate diencephalon plus a short midbrain, a hindbrain and a spinal cord [9-13] (Figure 1). The gene networks for patterning the anteroposterior and dorsoventral axes of the neural tube are likely conserved between amphioxus and vertebrates [14-17]. Moreover, molecular and anatomical studies suggest that the amphioxus and vertebrate brain are characterized by several homologous structures: the frontal eye complex (homolog of the vertebrate lateral eyes), the lamellar body (homolog of the vertebrate epiphysis), and the infundibulum [12] (Figure 1). Unlike vertebrates, the neural tube of amphioxus does not possess morphologically segmented rhombomeres.

\section{Biomed Central}




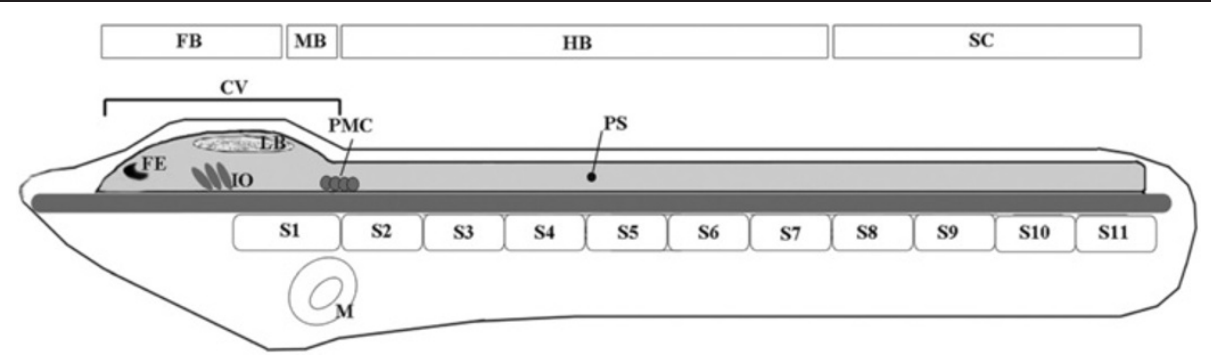

Figure 1 Schematic representation of an amphioxus early larva. The central nervous system (CNS) of an amphioxus early (36-hr) larva includes an anterior cerebral vesicle (CV), which, anteriorly, contains a frontal eye complex (FE) and, posteriorly, the infundibular organ (IO) as well as the lamellar body (LB). At the posterior end of the $\mathrm{CV}$, there is a small midbrain-like region that includes the tectal zone extending from the posterior of the lamellar body to the anterior of the primary motor center (PMC). Posterior to the CV, the amphioxus CNS is divided into a hindbrain-like region, (extending from the posterior part of the PMC to the boundary of somites 7 and 8) and a territory corresponding to the vertebrate spinal cord. FB, forebrain; MB, midbrain; HB, hindbrain; SC, spinal cord; PS, first pigment spot; S, somite; N, notochord; $M$, mouth.

Collinear expression of Hox genes as well as the segmental expression patterns of genes, such as islet and ERR, nonetheless suggest that the amphioxus CNS contains a regionalized hindbrain [16,18-20] and some authors have proposed that the establishment of this hindbrain organization requires signaling from the segmented mesoderm [20]. Neurotransmitter chemistry has been relatively conserved through metazoan evolution, while brain size and cytoarchitecture have been altered considerably in different lineages, particularly in vertebrates. Therefore, amphioxus, with its simple vertebrate-like CNS, is a favorable model for studying the evolution of chordate and vertebrate neuroanatomy and neurophysiology. In a previous study, we have identified a gene encoding amphioxus tyrosine hydroxylase (AmphiTH), the rate-limiting enzyme for dopamine (DA) biosynthesis and studied the localization of dopaminergic neurons during amphioxus development [21]. Similarly, we have studied the appearance of cholinergic neurons by assessing the expression of choline acetyltransferase (ChAT) and vesicular acetylcholine transporter (VAChT) [22]. By double whole-mount in situ hybridization, we demonstrated that VAChT and ChAT are coexpressed in the same cells of the amphioxus neural tube. Moreover, both amphioxus VAChT and ChAT are alternative transcripts generated from a single gene locus (cholinergic gene locus or CGL) [22]. Moreover, the serotonergic system has been investigated by immunocytochemistry in amphioxus embryos and larvae $[23,24]$.

Here, we use neurotransmitter markers in amphioxus to reconstruct a neurochemical map of the developing cephalochordate nervous system. Using vesicular transporters and key enzymes for neurotransmitter biosynthesis as markers, we assessed the neuronal differentiation in the developing amphioxus nervous system focussing on the time of appearance of glutamatergic, GABAergic, glycinergic, cholinergic and serotonergic neurons. Although we are aware that physiological and pharmacological assays are required to definitively demonstrate the utilization of a specific neurotransmitter by a given amphioxus neuron, our work nonetheless revealed the distribution of neuronal cell bodies engaged in synthesizing particular neurochemicals in the developing amphioxus CNS and allowed us to construct the first neurochemical map of the amphioxus embryo.

\section{Results}

In order to classify the neurons of the developing amphioxus CNS on the basis of their neurotransmitter properties, we cloned genes encoding vesicular transporters and/or key enzymes for transmitter synthetic pathways and studied their expression by whole mount in situ hybridization (Table 1). Glutamatergic neurons were identified by using as marker the vesicular glutamate transporter (VGLUT), which in vertebrates is required for glutamate accumulation and transmission. In the genome of the Florida amphioxus (Branchiostoma floridae), we found four potential VGLUT-related sequences (Additional file 1). Phylogenetic analyses established that only one of the four sequences is a true ortholog of the three vertebrate VGLUT sequences (Additional file 1 and Additional file 2). This amphioxus VGLUT gene was

$\begin{aligned} & \text { Table } \mathbf{1} \text { List of the genes, encoding vesicular transporters } \\
& \text { and/or key enzymes for neutransmitter biosynthesis, } \\
& \text { studied in the present work }\end{aligned}$
\begin{tabular}{lll}
\hline Neurotransmitter & Transporter & Biosynthetic enzyme \\
\hline Glutamate & $\begin{array}{l}\text { Vesicular Glutamate } \\
\text { Transporter (VGLUT) }\end{array}$ & \\
Serotonin (5-HT) & $\begin{array}{l}\text { Serotonin Transporter } \\
\text { (SERT) }\end{array}$ & $\begin{array}{l}\text { Tryptophan Hydroxylase } \\
\text { (TpH) }\end{array}$ \\
GABA & $\begin{array}{l}\text { Vesicular GABA/Glycine } \\
\text { Transporter (VGAT) }\end{array}$ & $\begin{array}{l}\text { Glutamic Acid } \\
\text { Decarboxylase (GAD) }\end{array}$ \\
Glycine & $\begin{array}{l}\text { Vesicular GABA/Glycine } \\
\text { Transporter (VGAT) }\end{array}$ & \\
Acetylcholine (ACh) & $\begin{array}{l}\text { Vesicular Acetylcholine } \\
\text { Transporter (VAChT) }\end{array}$ & \\
\hline
\end{tabular}


subsequently isolated by PCR and used to synthetize the riboprobe for in situ hybridization.

Amphioxus possesses at least one ortholog of the mammalian genes encoding tryptophan hydroxylase $(\mathrm{TpH})$, the rate-limiting enzyme in serotonin synthesis and a serotonin transporter (SERT) acting as both symporter and antiporter in the presynaptic membrane (Additional file 1 and Additional file 2). Amphioxus $T p H$ and SERT served as molecular markers for locating the serotonin-producing neurons in the developing amphioxus nervous system. Both markers show the same expression pattern and are likely expressed at very low levels, because, compared to the other neurotransmitter markers used in the present work, both required an extended development time with the alkaline phosphatase-mediated detection system. We were thus unable to obtain very strong signals in our double in situ hybridization experiments with these two markers.

To follow the differentiation of GABAergic neurons in amphioxus, we studied the expression of glutamic acid decarboxylase (GAD), the rate-limiting enzyme in GABA biosynthesis. Moreover, we simultaneously assessed the developmental expression of the vesicular GABA/glycine transporter (VGAT) that is responsible for the uptake into the synaptic vesicle of both GABA and glycine [25]. We found that amphioxus possesses single genes encoding $G A D$ and $V G A T$ (Additional file 1 and Additional file 2), both of which were cloned by PCR. However, since VGAT is expressed in both GABAergic and glycinergic neurons [25], in order to identify the glycinergic neurons in the amphioxus CNS, we needed to perform double in situ hybridization experiments with both $G A D$ and $V G A T$. Thus, GABAergic neurons are $V G A T$-positive and $G A D$-positive, while glycinergic neurons are $V G A T$-positive and GAD-negative.

Finally, we used double in situ hybridization to obtain more synoptic maps of neurochemically-marked neurons (Figures 2 and 3). In addition to VGAT and VGLUT, we also included the gene encoding the amphioxus vesicular acetylcholine transporter (VAChT) as marker for cholinergic neurons. We hence analyzed embryos doublestained for VGAT and VGLUT, VGLUT and VAChT as well as VGAT and VAChT.

\section{Glutamatergic neurons}

Expression of amphioxus VGLUT is first detectable in the CNS of the 14-hr neurula in three pairs of cells located, respectively, in the anterior tip of the CNS, at posterior end of the cerebral vesicle and in close proximity of the first pigment spot (Figures 2 and 4A). At this stage, VGLUT is also expressed in ectodermal cells located at the anterior tip of the embryo and ventrolaterally on both sides of the embryo (Figure 4A). The

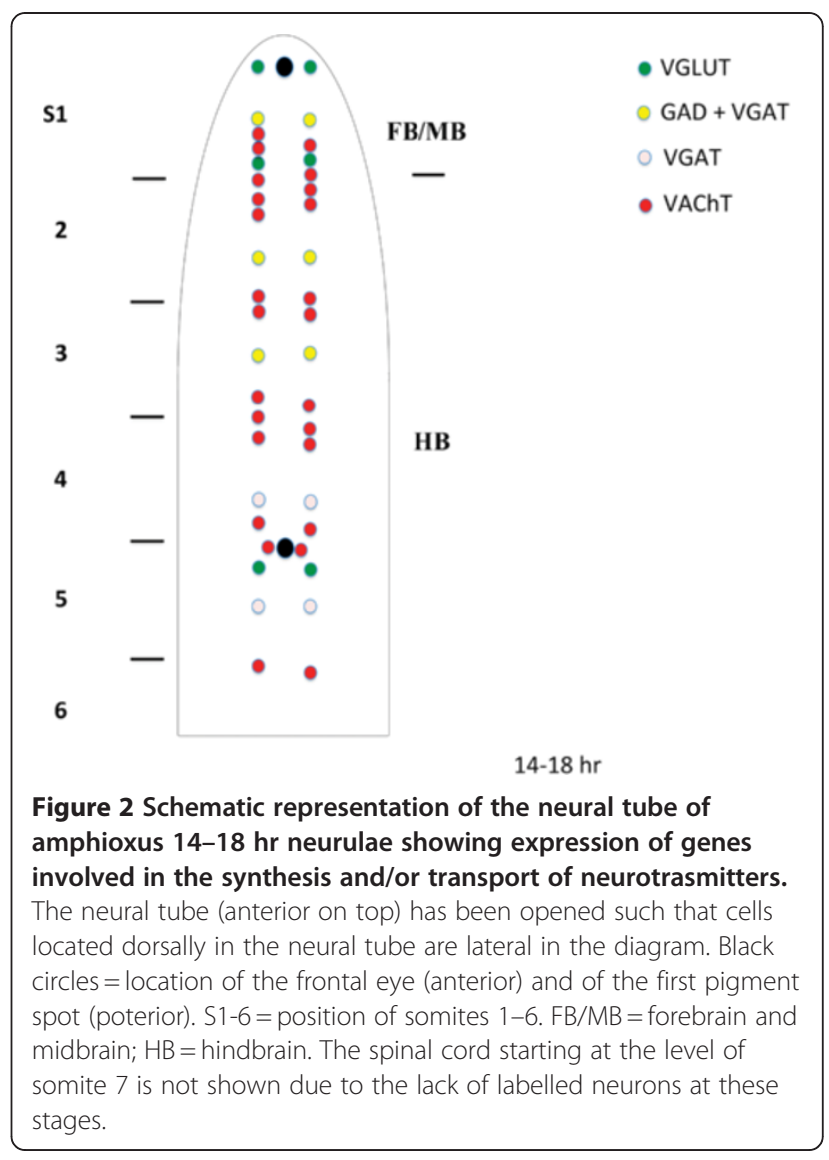

latter ectodermal cells probably correspond to type 1 ectodermal sensory cells [26,27], which originate ventrally and migrate dorsally during the neurula stage. VGLUT expression remains essentially unchanged in the 16-hr neurula (Figures 2, 4B and C). At 22 hrs and $24 \mathrm{hrs}$, however, additional cells in the anterior CNS begin to express VGLUT, including cells located dorsolaterally in the anterior tip of the cerebral vesicle (Figures 3 and 4D-O). VGLUT expression is also found in dorsolateral and ventral cell bodies in proximity to the first pigment spot (Figures 3 and 4E-H). Moreover, scattered ectodermal cells along both flanks of the body are still labeled (Figure 4D-H). At 36 hrs, VGLUT transcription is initiated in the neural tube just anterior to the first pigment spot (Figure 4P). In 36-hr larvae, VGLUT-positive cells are also detectable in the anterior tip of the CNS at level of the frontal eye, in the posterior cerebral vesicle, in the neural tube anterior and posterior to the first pigment spot and in ectodermal sensory cells (Figure 4P).

\section{Serotonergic neurons}

TpH- and SERT-expressing neurons are located in 22-hr neurulae in the most anterior tip of the cerebral vesicle, where the frontal eye complex will develop (Figures 3, 


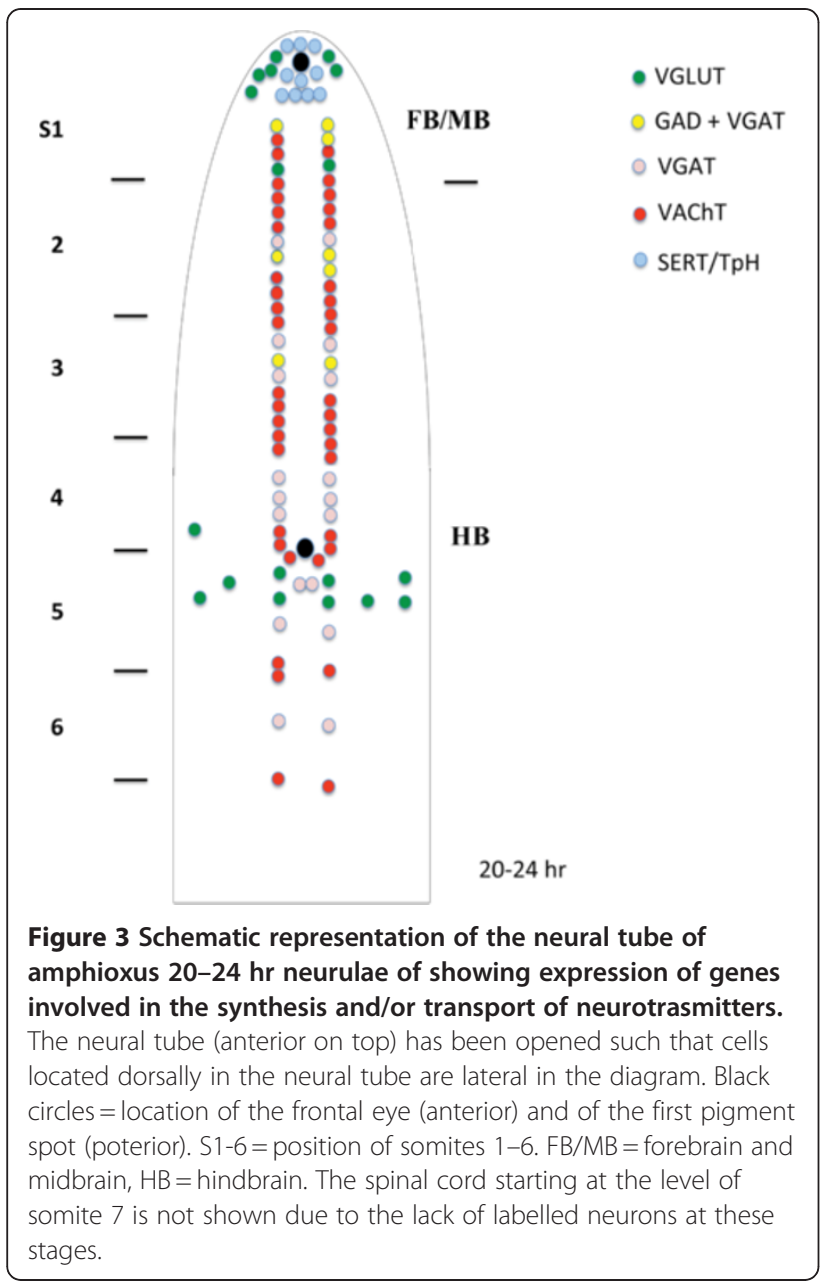

5A-C and 5E). By 24-hr, TpH-positive neurons are also detectable in ventrolateral cells of the cerebral vesicle (Figures 3 and 5F). Expression is essentially unchanged in the 72-hr larva (Figures 5D and G), with the notable exception of a few SERT-positive neurons that become detectable in the hindbrain region (Figure 5D).

\section{GABAergic and glycinergic neurons}

$G A D$ expression is first detectable in the $16-\mathrm{hr}$ neurula in three pairs of cells in the neural tube: one pair in the cerebral vesicle and two pairs in the hindbrain region (Figures 2 and 6A). Expression is unchanged in the 18hr neurula (Figure 6B). By 24-hr and 36-hr, the first two cell pairs have been replaced by two clusters of three cells each (Figures 3 and $6 \mathrm{C}$-E). GAD-expressing cells are arranged ventrolaterally in the neural tube (Figure 6F-H). By 48-hr, excepting the appearance of $G A D$-positive neurons anterior and posterior to the first pigment spot, the expression of GAD in the neural tube remains unchanged. At this stage, ectodermal sensory neurons around the oral cavity also express $G A D$ (Figure 6I).
Amphioxus VGAT expression is first observed in the 16-hr neurula in five pairs of cells (Figures 2 and 7A,C): one pair in the cerebral vesicle and four pairs, regularly spaced, in the hindbrain region. A cross-section shows expression of VGAT in the ventral neural tube, which is identical to the localization of GAD-positive neurons (Figure 7B). The overall expression pattern of $V G A T$ is maintained at later developmental stages, but the total number of VGAT-positive cells in each of the five cluster pairs increases with time (Figures 7D and E). At the midneurula stage (16-18 hr), glycinergic neurons correspond to the two posterior pairs of $V G A T$-positive/GAD-negative cells (Figures 2 and 8A-E). By the late neurula stage (22-hr), moving from anterior to posterior, the second cluster of labeled cells (at the level of somite 2) contains a mixture of glycinergic and GABAergic cells, while the third cluster (at the center of the somite 3) is characterized by at least one pair of GABAergic and two pairs of glycinergic neurons (Figures 3 and 8F,G). Both the fourth cluster and the labeled cells posterior to the first pigment spot maintain only a glycinergic phenotype (Figure 3 ). The VGAT and GAD expression patterns observed in late neurulae are still present at larval stages (data not shown).

\section{Construction of a neurochemical map in amphioxus by double in situ hybridization}

We found that, at the neurula stage (14 hrs to $18 \mathrm{hrs}$ ), the amphioxus CNS contains different types of neurons. In the cerebral vesicle (the equivalent of the vertebrate forebrain/midbrain), we found two pairs of VGLUTpositive cells, one located anteriorly and one located posteriorly (Figures 2 and 9A,B), and one pair of GAD/ $V G A T$-positive cells located in the center of the cerebral vesicle (Figures 2 and 8A,D). Moreover, in the 14-18 hr neurula, there is also one pair of VAChT-positive cells detectable in the cerebral vesicle (Figures 2 and 10A-C). The more posterior regions of the neural tube, starting at the level of somite 2 and extending to the boundary of somites 4 and 5 , is characterized by a mixture of $V A C h T$-labeled neurons and GAD/VGAT-positive (at the level of somites 2 and 3) or VGAT-positive/GAD-negative (at the level of somite 4) neurons (Figures 2, 8A-E and 11A-D). Importantly, the VAChT-positive and GAD-/VGAT-positive or VGAT-positive/GAD-negative neurons are organized into alternating clusters of cells (Figures 2, 8A-E and 11A-D). At the junction between somites 4 and 5 , which corresponds to the region of the neural tube where the first pigment spot is forming, $V A C h T$-, VGLUT- and VGAT-expressing neurons are organized into an anteroposterior array of cells (Figures 2, 9A and $\mathrm{B}, 10 \mathrm{~A}$ and $\mathrm{C}, 11 \mathrm{~A}-\mathrm{D})$.

These expression patterns are maintained in later neurula stages (20 hrs to $24 \mathrm{hrs}$ ) (Figures 3, 9C-E, 10D-G and 

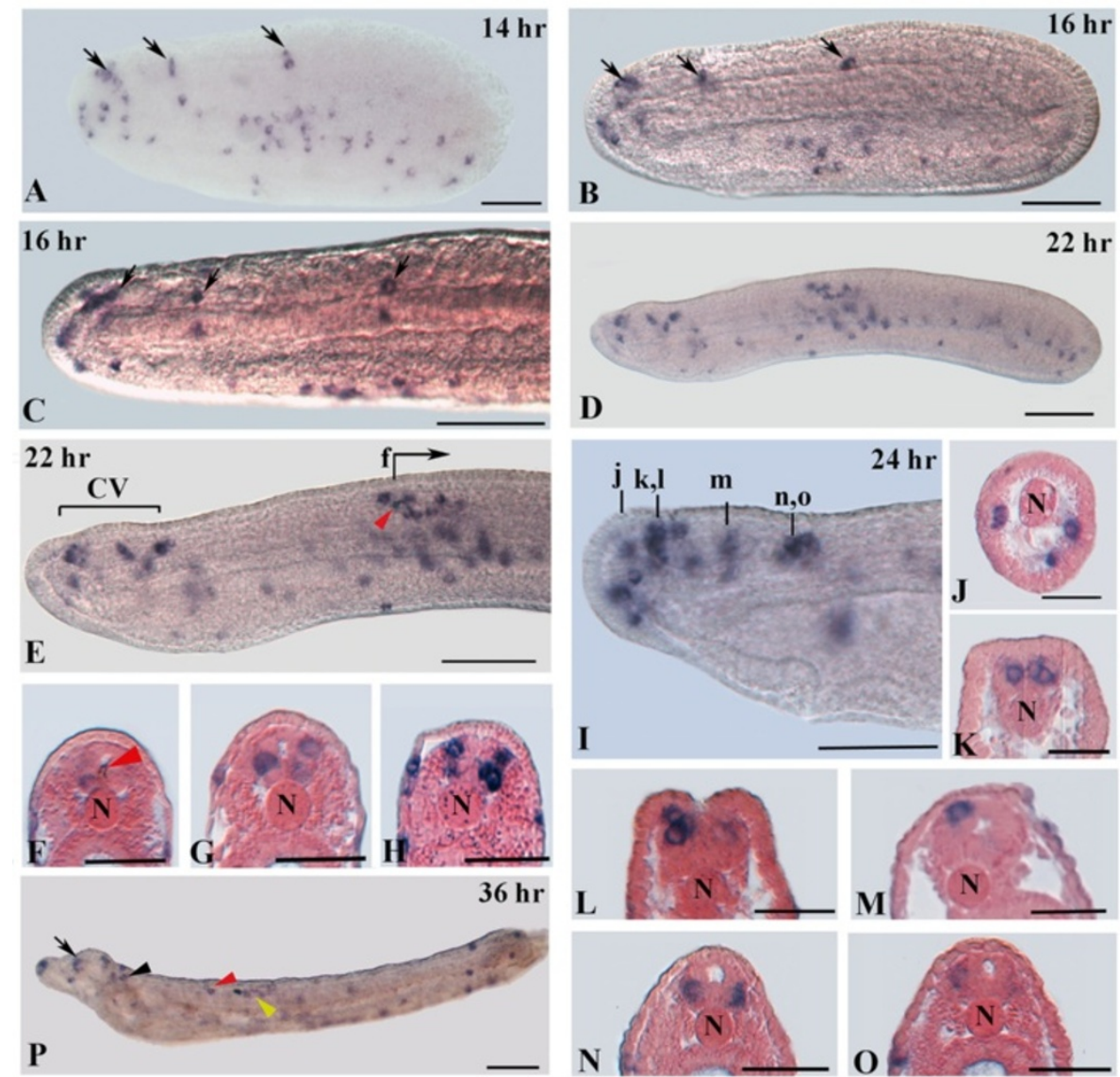

Figure 4 VGLUT expression in developing amphioxus embryos. Whole mounts with anterior to the left (scale bars $=50 \mu \mathrm{m}$ ) and crosssections (scale bars $=25 \mu \mathrm{m}$ ) viewed from the caudal end of the animal. A: 14-hr neurula showing expression in single ectodermal cells in the ventrolateral region and in three spots of the neural tube (arrows). B: 16-hr neurula with expression in three spots of the neural tube (arrows). C: Dorsal view of the embryo in B showing three pairs of VGLUT positive neurons in the neural tube (arrows). D: Side view of a 22-hr neurula. E: Magnification of the anterior part of the embryo in D, showing expression in three cell clusters of the cerebral vesicle (CV) and in several neurons located in close proximity to the first pigment spot. Labeled ectodermal sensory cells are conspicuous near the first pigment spot. F-H: Consecutive transverse sections starting at the level of $\mathrm{f}$ in E. I: Anterior end of a 24-hr larva. J-O: Transverse sections at levels indicated in I. P: 36-hour larva. Several labeled sensory cells are visible along the body of the larva and at the tip of the rostrum. VGLUT transcripts are also detectable in cells of the frontal eye complex (arrow), in neurons of the posterior cerebral vesicle (black arrowhead) and in cells of the neural tube anterior (red arrowhead) and posterior (yellow arrowhead) to the first pigment spot. N, notochord. The first pigment spot in E, N and P is indicated by a red arrowhead.

$11 \mathrm{E}, \mathrm{F})$, with the notable exception of the appearance of two groups of VGLUT-positive neurons: one located dorsally in the anterior cerebral vesicle (Figures 3,9C and E, $10 \mathrm{D}, \mathrm{E}, \mathrm{G})$ and one located posterior to the first pigment spot (Figures 3 and 10E-G). Moreover, we observed that the total number of neurons constituting the VGAT and $V A C h T$ clusters increased at these later stages (Figures 3, $9 \mathrm{C}-\mathrm{E}, 10 \mathrm{D}-\mathrm{G})$. At larval stages, there is no substantial difference in the basic organization of neuronal cell types in the amphioxus CNS except for an additional increase in the total number of neurons constituting the VGAT and $V A C h T$ clusters (Figures 9F and G, 10H-K).

Taken together, our in situ hybridization experiments yielded a neurochemical map of the developing amphioxus CNS. Surprisingly, this map suggests that, at least in the developmental stages examined, neurotransmitters do not colocalize in the amphioxus CNS. This finding contrasts with some examples of neurochemical colocalization observed in mollusks and vertebrates [28-30].

\section{Discussion}

In the present work, we have studied the development of specific neuronal groups defined by their neurotransmitter phenotype in the amphioxus B. floridae and have compiled a synoptic neurochemical map of the developing amphioxus nervous system (Figures 12 and 13). This is an advance over previous studies of amphioxus neurons, which were limited to elucidating only one neurotransmitter or neuropeptide at a time and which have 

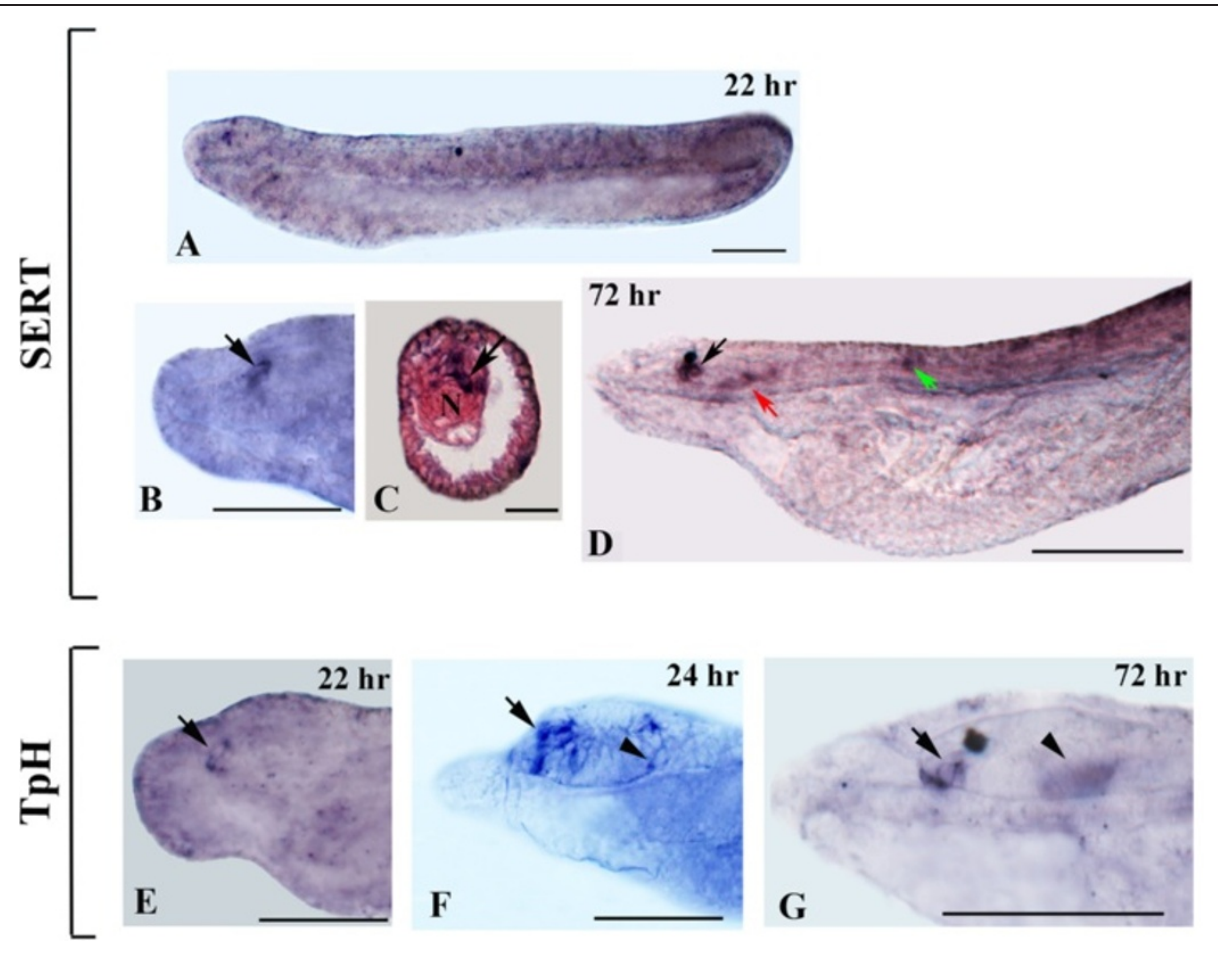

Figure $\mathbf{5 T p H}$ and SERT expression during amphioxus development. Whole mounts with anterior to the left. The cross-section in $\mathbf{C}$ is viewed from the caudal end of the animal. Whole mount and section scale bars are $50 \mu \mathrm{m}$ and $25 \mu \mathrm{m}$, respectively. A: Side view of a 22-hour embryo. B: Magnification of the anterior end of the embryo in $\mathbf{A}$ showing SERT-positive cells in the most anterior tip of the neural tube (arrow). C: Crosssection through the most anterior labeled cells in B (arrow). D: Anterior portion of a 72-hour larva. Transcripts are detectable in cells of the frontal eye complex (black arrow), in the center and posterior end of the cerebral vesicle (red arrow) and in cells in the hindbrain region (green arrow). E: Anterior end of a 22-hr embryo showing TpH expression in the precursor region of the frontal eye complex (arrow). F,G: TpH expression in the anterior end of 24-hr and 72-hr larvae, respectively. TpH is expressed in cells of the frontal eye (arrow) and in ventrolateral cells of the cerebral vesicle (arrowhead). N, notochord.

demonstrated, for example, the occurrence in amphioxus of neurons containing cholecystokinin, oxytocin, vasopressin, luteinizing hormone and FMRFamide [31,32]. More recently, serotonergic, dopaminergic and cholinergic neurons have also been reported in B. floridae embryos and larvae [21-24], and the distribution of dopamine, serotonin and GABA has been described in amphioxus adults [33,34]. Moreover, by using HPLC, glutamate, aspartate, glycine, alanine, serine and GABA have been identified in the nervous system of the amphioxus B. lanceolatum [35].

\section{Interpreting the organization of neuronal cell types in the developing amphioxus nervous system}

Previous ultrastructural studies on the architecture and cellular organization of the larval amphioxus CNS have provided a detailed morphological map of different neuronal types [37-39]. The majority of these transmission electron microscope (TEM)-based neuroanatomical reconstructions in amphioxus have been carried out on 8-day and 12.5-day larvae and thus on developmental stages older than the material used in the present study. Comparisons of these morphological data with our neurochemical map will hence need to take these stage differences into account.

On the basis of morphological and topological features, three types of motoneurons have been identified in the ventrolateral nerve cord of amphious larvae: (i) dorsal compartment motoneurons (DC) innervating the dorsal fast fibers of the myotome, (ii) ventral compartment motoneurons $(\mathrm{VC})$ innervating the ventral slow fibers of the myotome, (iii) visceral motoneurons (VM) innervating all of the remaining body musculature (Figure 12). The DC motoneurons are confined to the most anterior somites and are generally organized as pairs of cells. According to Lacalli and Kelly [37] at least one pair of DC motoneurons is slightly offset and is located at the level of the center of somite 2, whereas all the other pairs (at least five) are positioned at the junction of the somites. Expression of amphioxus islet and $E R R$ genes coincides with prospective DC motoneurons $[19,20]$. VC motoneurons have no evident periodical arrangement along the nerve cord, although a cluster of five $\mathrm{VC}$ neurons is found at the level of the posterior end of somite $1[37,39]$. Finally, VM motoneurons seem to be very scarce in young larvae, but at least two have been described located posterior to the junction of somites 2 and $3[37,39]$. 

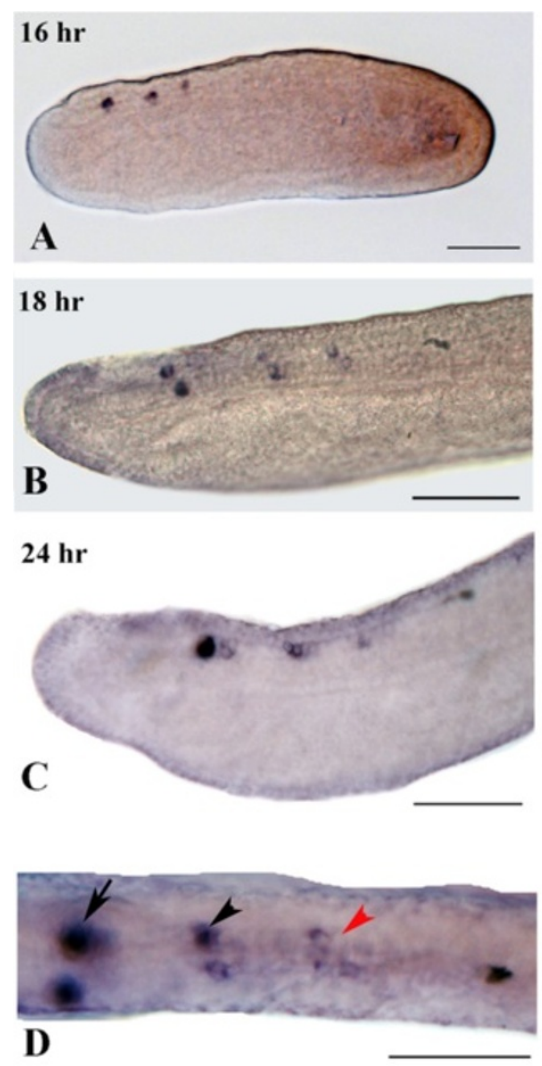
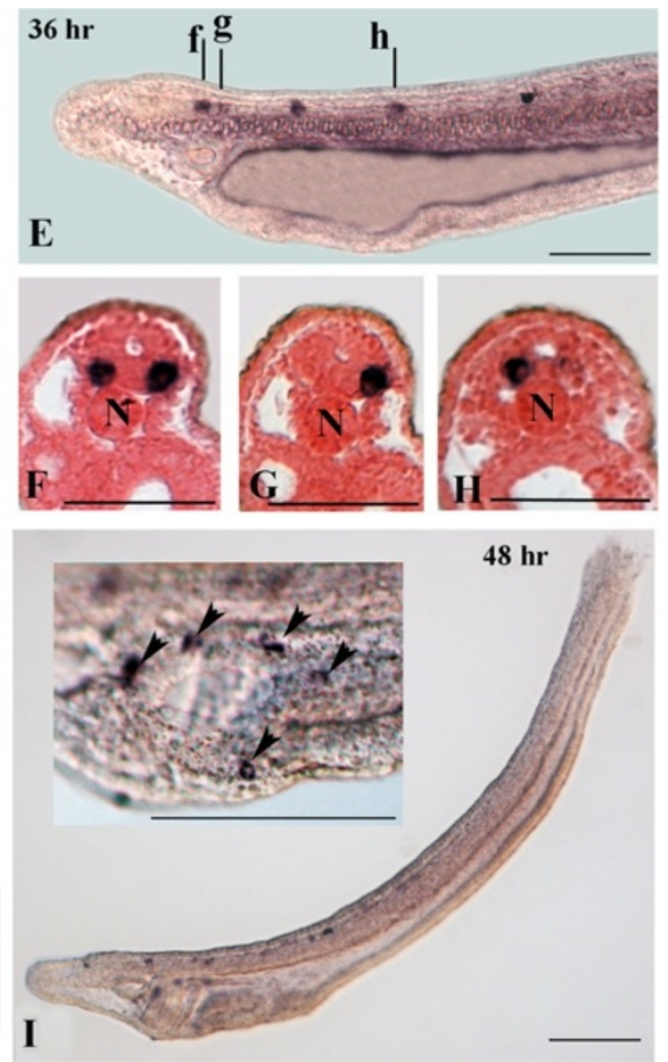

Figure 6 Expression of GAD during amphioxus development. Whole mounts with anterior to the left. The cross-sections in F-H are viewed from the caudal end of the animal. Whole mount and section scale bars are $50 \mu \mathrm{m}$ and $25 \mu \mathrm{m}$, respectively. A: Side view of a 16-hr neurula showing three spots of expression in the neural tube. B: Magnification of a 18-hr neurula showing three pairs of GAD-positive neurons. C: Anterior region of a 24-hr larva. D: Dorsal view of the embryo in C showing conspicuous expression in clustered neurons (arrow) at the posterior end of the cerebral vesicle. At more posterior levels of the neural tube, there are two more clusters of labeled neurons (black and red

arrowheads). E: Lateral view of a 36-hour larva. F-H: Cross-sections of the larva shown in $\mathbf{E}$ through levels f, $\mathrm{g}$ and h, respectively. I: Side view of 48-hour larva. The inset shows GAD-positive sensory cells around the oral cavity (arrowheads). N, notochord.

Additionaly, different interneurons have been reported in the amphioxus ventrolateral nerve cord [37,39]. At the ultrastructure level, four types of interneurons, described as large paired neurons (LPN1-4), are present in the amphioxus CNS (Figure 12). The first three at the level of the primary motor center (PMC) and the fourth at the level of the junction of somites 3 and 4 [37,39]. Moreover, four ipsilateral projection interneurons (IPNs) have also been described, located predominantly in the most rostral part of the hindbrain posterior to the first pair of DC motoneurons [37,39]. No information is available on the presence of other kinds of interneurons in more posterior regions of the amphioxus nerve cord.

In a previous report on the expression of the CGL (for cholinergic gene locus, i.e. ChAT/VAChT) [22], we have tentatively assigned a cholinergic neurotransmission to some of the ventrolateral neurons identified by TEM, most of which are motoneurons. This correlation of cell types identified by TEM and neurons expressing specific sets of neurotransmitters can now be expanded. We show, for instance, that cholinergic neurons are generally organized as discontinuous rows of cells starting anteriorly at the PMC and stretching posteriorly to the junction of somites 6 and 7 (Figure 3). Some of the most anterior cholinergic cells, located in proximity of the posterior end of somite 1 , are probably VC motoneurons, whereas the pairs of cholinergic neurons at the junctions of the somites (from somites 2 and 3 to somites 5 and 6) are likely DC motoneurons, plus an additional pair of neurons located at the level of somite 2 (Figures 3 and 12). Additionally, the cholinergic neurons located just posterior to the junction of somites 2 and 3 might correspond to VM motoneurons (Figures 3 and 12).

One subset of cholinergic neurons identified in the CNS of developing amphioxus are most likely interneurons [22], which would correlate very well with the situation in vertebrates [40]. For example, LPN3 located at 

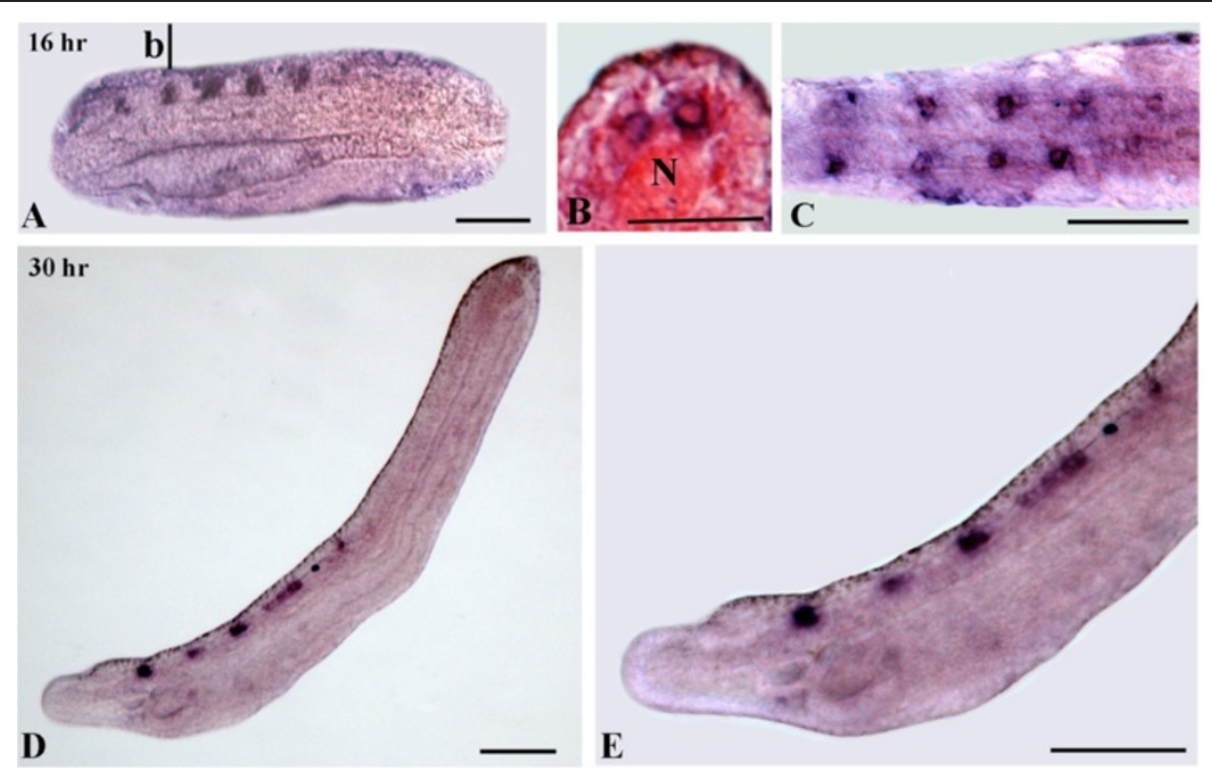

Figure 7 Expression of VGAT during amphioxus development. Whole mounts with anterior to the left. The cross-section in $\mathbf{C}$ is viewed from the caudal end of the animal. Whole mount and section scale bars are $50 \mu \mathrm{m}$ and $25 \mu \mathrm{m}$, respectively. A: Side view of a 16-hour neurula showing five spots of VGAT expression in the neural tube. B: Cross-section of the embryo in $\mathbf{A}$ through level b. Two ventrolateral neurons are expressing VGAT. C: Enlarged dorsal view of the embryo in $\mathbf{A}$ showing five pairs of VGAT-positive neurons. D: Side view of a 30-hour larva. E: Magnification of the larva in $\mathbf{D}$. N, notochord.

the junction of somites 1 and 2 is a potential candidate for such a cholinergic amphioxus interneuron, although LPN3 could alternatively be interpreted as a pair of glutamatergic excitatory neurons located inside the PMC (Figures 12 and 13). In contrast, our data suggest that the anterior LPNs (LPN1 and 2) and IPNs (on the level
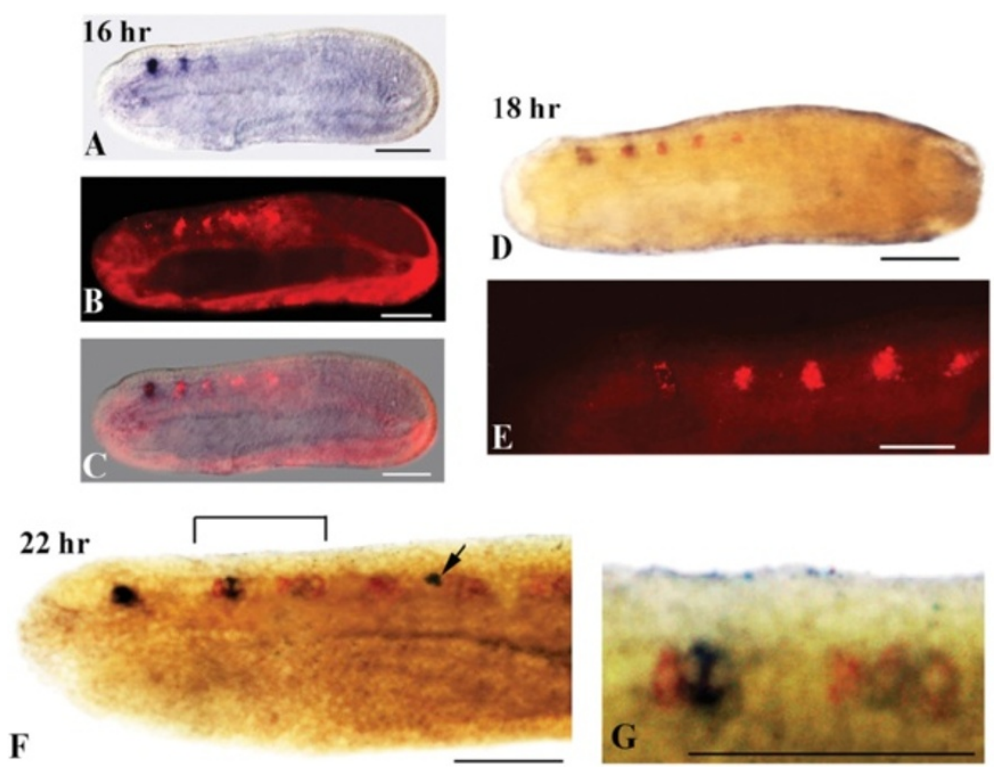

Figure 8 Overlapping expression of GAD and VGAT revealed by double in situ hybridization. Anterior is to the left and whole mount scale bars are $50 \mu \mathrm{m}$. A-C: Lateral views of a 16-hr neurula. A: GAD expression is detectable in three spots of the neural tube. B: Double-labeled embryo viewed by epifluorescence showing five pairs of VGAT-positive neurons. C: Merger of $\mathbf{A}$ and $\mathbf{B}$ showing the colocalization of GAD and VGAT in three anterior pairs of neurons. D,E: Lateral views of a 18-hr neurula. D: Double-labeled embryo. The dark brown staining shows coexpression of GAD and VGAT, while the red staining shows only VGAT expression. E: Magnification of the double-labeled embryo in $\mathbf{F}$ showing VGAT-positive neurons in epifluorescence. F,H: Double-labeled 22-hr neurula. F: Magnification showing GAD and VGAT co-expression (dark brown) and VGAT expression (red). The arrow indicates the first pigment spot. G: Magnification of the bracketed region in F. 


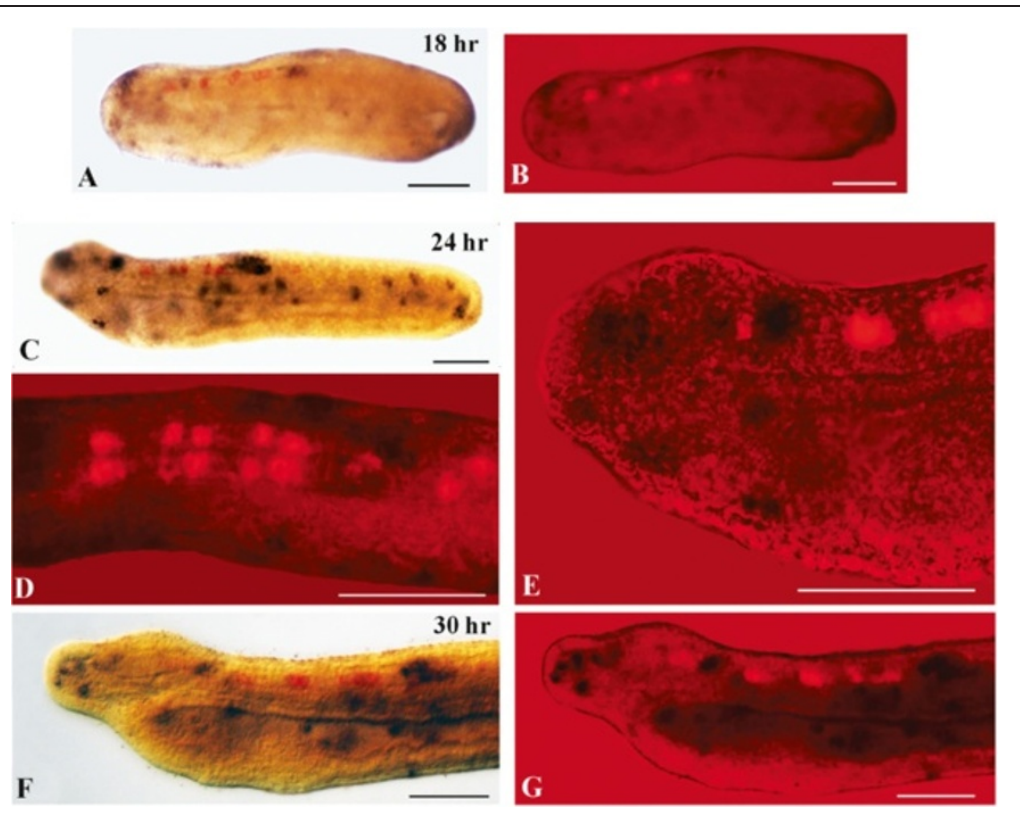

Figure 9 Double in situ hybridization of VGAT and VGLUT. Whole mounts with anterior to the left. Whole mount scale bars are $50 \mu \mathrm{m}$. In $\mathbf{A}$, $\mathbf{C}$ and $\mathbf{F}$ the dark purple staining shows VGLUT expression, while the red staining shows VGAT expression. B, D, E and $\mathbf{G}$ show a superimposition of brightfield and epifluorescence with VGLUT- and VGAT-positive neurons. A,B: Side view of a 18-hr neurula. C: Side view of a 24-hr larva. D: Magnified dorsal view of the larva shown in C. E: Magnified anterior part of the larva in C. F,G: Side view of the anterior third of a 30-hr larva.

of somite 2) are GABAergic and GABAergic/glycinergic, respectively (Figures 12 and 13).

In our neurochemical map, some neurons cannot be ascribed to one of the categories of motoneurons and interneurons identified by TEM [37]. This is, for instance, the case for the cluster of cholinergic, glycinergic and glutamatergic neurons located just posterior to the first pigment spot as well as for the aggregation of a number of different neuronal types (expressing $G A B A$, VGLUT or ChAT) at the level of the PMC (Figures 12 and 13). The PMC is a major integrative center of sensory and motor stimuli controlling the early locomotory activities of the larva, which could explain this concentration of different neuronal types. Moreover, the PMC interneurons (GABAergic and glutamatergic) probably connect to rostral sensory cells and project towards the posterior nerve cord, which likely contributes to locomotion and the startle response $[41,42]$.

\section{GABAergic and glycinergic neurons in vertebrates and invertebrates}

GABA is a major inhibitory neurotransmitter in both vertebrates and invertebrates [43-46]. In comparison to other animals, the distribution of GABA in the CNS of amphioxus embryos and larvae seems to be more discrete. In the CNS of the ascidian Ciona intestinalis, GABA is widely expressed and is associated with neural regions responsible for processing sensory information and motor integration, such as the sensory vesicle and the anterior visceral ganglion (Figure 13) [47]. Interestingly, while a majority of neurons of the sensory vesicle are GABAergic, only very few cells of the anterior visceral ganglion contain GABA [47]. In the $C$. intestinalis peripheral nervous system (PNS), there are only very few GABAergic cells, the majority of which are associated with the palps (Figure 13).

Unlike GABAergic cells, which are widespread in the vertebrate brain, most glycinergic neurons in the vertebrate CNS are restricted to the rhombencephalon and the spinal cord. For instance, in embryos of the frog Xenopus laevis the first glycinergic cells appear in the caudal hindbrain region and subsequently extend to the spinal cord [48], which was also observed in lamprey embryos $[49,50]$. In $C$. intestinalis larvae, two pairs of glycinergic neurons have been reported in the tail [51] (Figure 13). These cells, called ACINs (for anterior caudal inhibitory neurons), are located in the anterior nerve cord, just posterior to the cholinergic motoneurons of the visceral ganglion, and act as a component of a neural circuit controlling alternative muscle contraction of the larva.

The distribution of glycinergic neurons in amphioxus is quite similar to that observed in the vertebrate CNS. Two pairs of glycinergic cells are visible in the hindbrain region at the neurula stage. At subsequent stages of development, two further clusters, intermingled with 

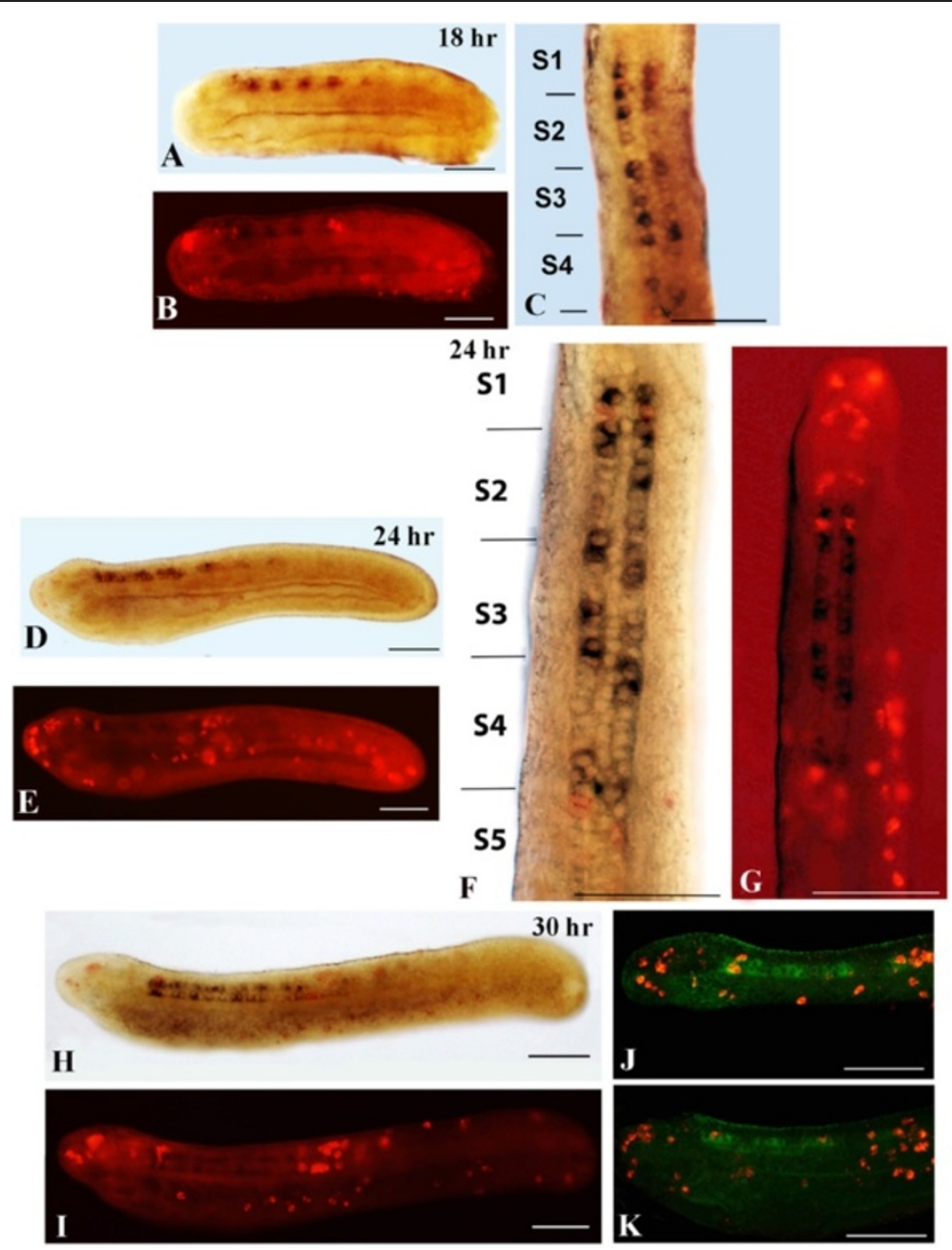

Figure 10 Double in situ hybridization of VAChT and VGLUT. Whole mounts with anterior to the left, except for $\mathbf{C}$, F and $\mathbf{G}$, where anterior is up. Whole mount scale bars are $50 \mu \mathrm{m}$. In $\mathbf{A}, \mathbf{C}, \mathbf{D}, \mathbf{F}$ and $\mathbf{H}$, the dark purple and red staining, respectively, show VAChT and VGLUT expression. In $\mathbf{B}, \mathbf{E}, \mathbf{G}$ and $\mathbf{I}$, the superimposition of brightfield and epifluorescence shows VAChT- and VGLUT-positive neurons. A,B: Lateral views of a 18-hr neurula. C: Dorsal view of the embryo in $\mathbf{A}$ and $\mathbf{B}$. D,E: Lateral views of a 24-hr neurula. F,G: Dorsal views of the embryo in $\mathbf{D}$ and $\mathbf{E}$. H,I: Lateral views of a 30-hr larva. J,K: Serial confocal fluorescence images of the embryo in $\mathbf{H}$ and $\mathbf{I}$. S, somite.

GABA cells, appear more anteriorly at the level of somites 2 and 3 (Figure 13). The present results thus reveal a dynamic developmental pattern of the glycinergic system in amphioxus, including early and late glycinergic neuron populations that might correlate with maturation changes occurring during brain differentiation.

\section{Comparison of glutamatergic neurons in vertebrates and invertebrates}

Glutamate is the predominant excitatory neurotransmitter in the CNS of invertebrates and vertebrates $[52,53]$. Glutamate is also one of the major neurotransmitters used in the vertebrate retina pathway, with the three VGLUTs being differentially expressed in specific classes of retina neurons [54]. Glutamate is further known to be present in the vestibular hair cells of different vertebrates [55-57] as well as in mechanosensory neurons of invertebrates [58]. In C. intestinalis, one VGLUT gene has been identified, which is expressed in both the central and the peripheral nervous system (Figure 13) [58]. More specifically, VGLUT is found in sensory organs (photoreceptor cells of ocellus and otolith) and interneurons of the posterior sensory vesicle. Moreover, most of the peripheral sensory neurons found in the larval head and tail are also glutamatergic.

In amphioxus, VGLUT is expressed at the neurula stage in a few cells of the nerve cord and in subpopulations of ectodermal cells. These ectodermal cells correspond to a subgroup of primary sensory cells expressing neural markers, such as Hu/Elav, ERR, $\beta$ tubulin, Delta, Brn3 (POU-IV) and synapsin [20,5963]. In the amphioxus CNS, glutamatergic neurons 


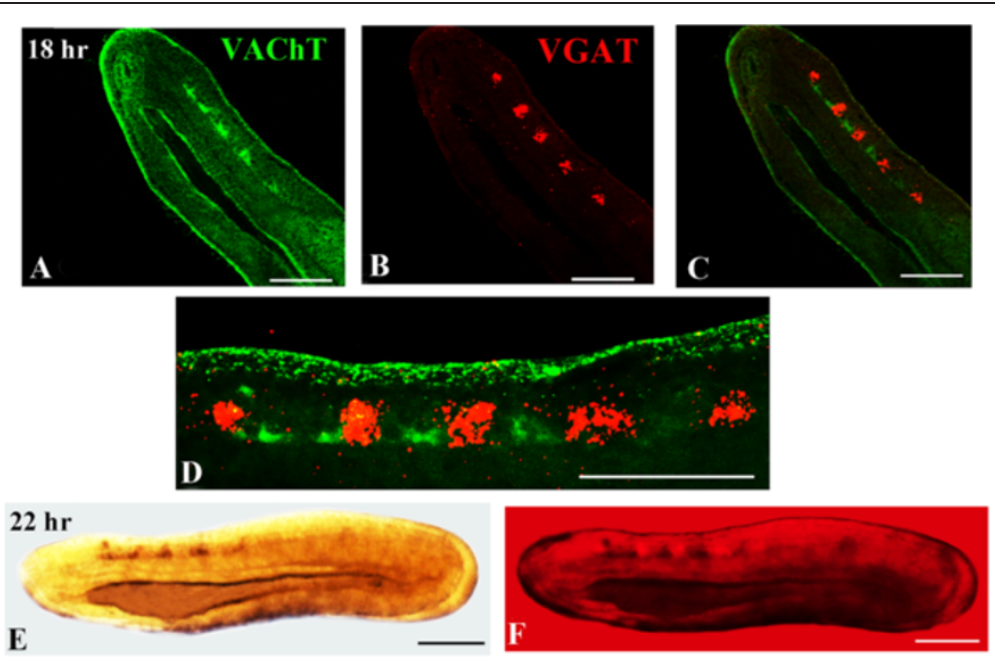

Figure 11 Double in situ hybridization of VAChT and VGAT. Whole mounts with anterior to the left and whole mount scale bars are $50 \mu \mathrm{m}$. A-D: Serial confocal fluorescence images of a 18-hr neurula. A: VAChT-positive neurons (green). B: VGAT-positive neurons (red). C: Merger of $\mathbf{A}$ and B. D: Magnification of the anterior neural tube shown in C. E,F: Lateral views of a 22-hr neurula. In E, the dark purple and red staining respectively show VAChT and VGAT expression. In $\mathbf{F}$, the superimposition of brightfield and epifluorescence shows both VAChT-positive and VGATpositive neurons.

are detected in the most anterior and the central region of the cerebral vesicle (Figure 13). Moreover, whereas most of the amphioxus hindbrain is devoid of glutamatergic cells at least until 36-hr, a cluster of VGLUT cells is present in the PMC. The expression of VGLUT in some cells of the frontal eye complex of amphioxus suggests that, comparable to vertebrate retina cells, some of the photoreceptor cells and/or neurons in amphioxus are also glutamatergic. The posterior end of the amphioxus hindbrain, caudal to the first pigment spot, contains clusters of ventrolateral and dorsolateral VGLUT cells (Figure 13). The dorsolateral cluster has previously been homologized with Rohon Beard sensory neurons expressing the neural marker islet [19,37]. Since several anamniote vertebrates exhibit Rohon Beard sensory neurons with a glutamatergic phenotype $[64,65]$, our data lend further support to this homology and suggest that glutamatergic transmission is likely to be a common feature of at least certain chordate sense organs.

\section{The serotonergic and dopaminergic systems}

Serotonin $(5-\mathrm{HT})$ is one of the most widespread signaling molecules of metazoans [66-68] and probably even of single-celled eukaryotes, where it can modulate swimming behavior and growth [69]. Dopamine (DA), a neurochemical molecule belonging to the catecholamines, has been identified in most metazoan phyla and hence represents another ancient neurotransmitter [70].

In tetrapod vertebrates, 5-HT neurons are located mainly in the raphe region of the hindbrain, whereas DAsynthesizing nuclei are located within the forebrain and the midbrain [71]. However, in teleosts, for example, 5-HT neurons are also conspicuous in the hypothalamus, where serotonin can modulate neurohormone secretion [72-75]. It is well known that Shh and FGF8 signaling provide essential information to specify the fates and initial positions of DA and 5-HT neurons in the ventral midbrain and rostral hindbrain of vertebrates. These signaling cascades also seem to be important for the expression of early neural patterning genes, such as Pax2, Pax5, Wnt1 and Engrailed, which establish a fundamental organizing center at the boundary of the midbrain and the hindbrain [76]. This midbrain-hindbrain boundary (MHB) acts as organizing center to direct the patterning of the adjacent neural territories and of the localization and size of the DA and 5-HT cell populations [71].

In the $C$. intestinalis larva, the $T p H$ gene is expressed in cells of the visceral ganglion [77], whereas the $T H$ gene (that encodes the tyrosine hydroxylase enzyme involved in DA synthesis) is expressed in the coronet cells of the ventral sensory vesicle, a region possibly homologous to the vertebrate hypothalamus (Figure 13) [33]. In amphioxus, 5-HT neurons are mainly located in the cerebral vesicle, whereas TH-labeled cells were described in the lamellar organ and adjacent ventrolateral cells (Figure 13) [21]. Taken together, since in amphioxus the first serotonergic and dopaminergic populations appear very close together in the cerebral vesicle, the ontogeny of the serotonergic and dopaminergic systems in amphioxus seem to differ substantially from the ontogeny of these systems in vertebrates. This difference between amphioxus and vertebrates might not be surprising given the absence in amphioxus of a 


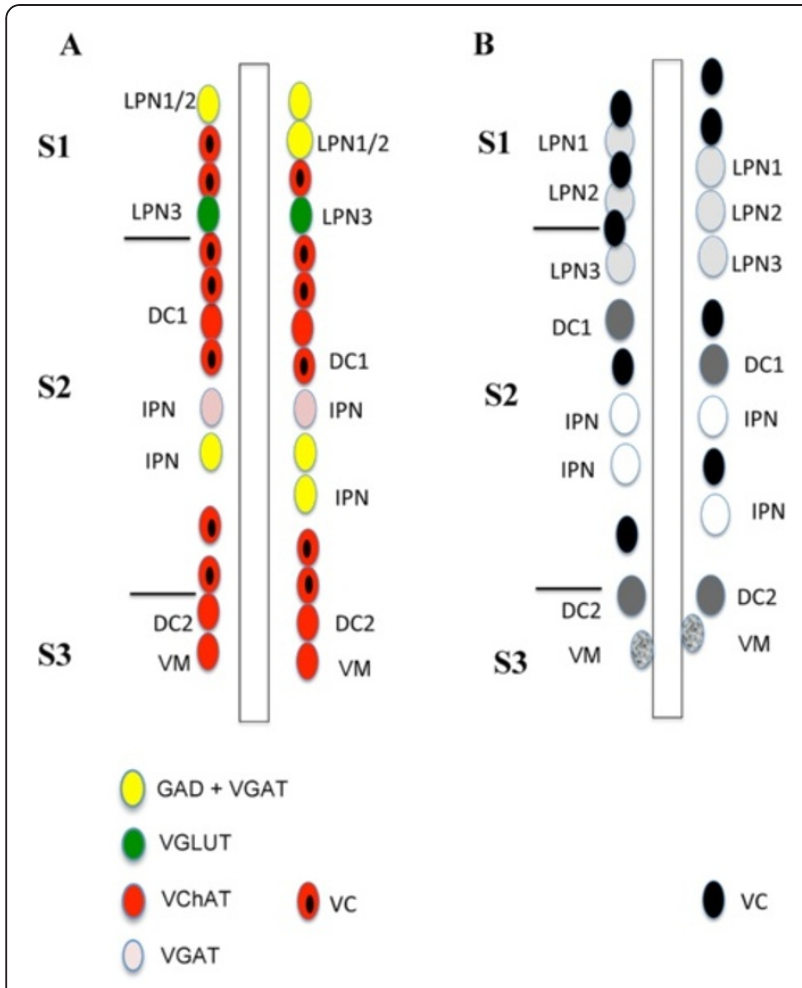

Figure 12 Comparison of neurotransmitter cell types in amphioxus embryos with the distribution of ventrolateral neurons in amphioxus larvae. A: Neurochemical map of amphioxus 20-24 hr embryos. B: Distribution of ventrolateral neurons in amphioxus 8-12.5 day larvae. Anterior is up and neuronal distribution is indicated only until the level of somite 3. Boundaries between somites $(\mathrm{S})$ are used to indicate the relative position of different cell types in the neural tube. Motoneuron populations include dorsal compartment motoneurons (DC), ventral compartment motoneurons (VC) and visceral motoneurons (VM). Interneuron populations include the large paired neurons (LPN) and the ipsilateral projection neurons (IPN).

vertebrate-like MHB organizer, which, in vertebrates, is required for defining the size and localization of the DA and 5-HT cell populations $[78,79]$.

\section{Conclusions}

Our neurochemical map of the amphioxus CNS reveals that the developing amphioxus nervous system is characterized by a strict regionalization and segmented organization of discrete groups of neuronal cell types. At the neurula stage, GABAergic/glycinergic as well as cholinergic neurons show a segmented distribution in the hindbrain, while glutamatergic, serotonergic and dopaminergic neurons are detectable in very restricted groups of neurons with precise locations along the anteroposterior axis of the CNS.

\section{Methods}

Animal collection and RNA preparation

Amphioxus adults (B. floridae) were collected in Tampa Bay, Florida, USA, and electrostimulated to induce gamete release. Eggs were fertilized, and embryos were cultured and fixed according to the published methods [80]. Embryos were collected at appropriate stages by low speed centrifugation and were frozen for RNA extraction or fixed for whole mount in situ hybridization. Following RNA extraction, the RNA was treated with RNAse-free DNAse I (Ambion Europe, UK) according to the manufacturer's recommendations to remove contaminating genomic DNA. First-strand cDNA was synthesized with $5 \mu \mathrm{g}$ of RNA using the SuperScript first-strand synthesis system (Invitrogen, USA) and oligo (dT) primers.

\section{Gene cloning and sequence analyses}

The B. floridae genome sequence [81] was screened with vertebrate and invertebrate VGAT, GAD, SERT, TpH and VGLUT sequences using the TBLASTN algorithm [82] to identify candidate gene fragments. The automated gene annotation of the retained amphioxus sequences was verified and expanded by protein predictions obtained with the GenScan [83] and GenomeScan [84] programs. The resulting amino acid sequences of the amphioxus VGAT, GAD, SERT, TpH and VGLUT candidates were aligned with different vertebrate and invertebrate VGAT, GAD, SERT, TpH and VGLUT sequences using Clustal W v.1.83 [85] and subjected to phylogenetic tree reconstruction analyses. The phylogenetic trees were reconstructed using the Neighbor Joining (NJ) and Maximum Likelihood (ML) methods with distance estimated by JTT amino acid matrix implemented in the program MEGA 5 [86]. Robustness of the resulting trees was calculated by bootstrap analyses in 1,000 replicates. The sequences used for calculating the phylogenies are provided in Additional file 1 and the resulting trees are presented in Additional file 2.

In sum, the in silico analyses yielded single amphioxus VGAT, GAD, SERT, TpH and VGLUT sequences that were used to design specific primers for PCR amplification. The following primers were used to amplify partial sequences of: VGAT, 5' primer GGTCCAGTGTTTGTACGAGGA and 3' primer GATCCCACTTCAGCTTCATGT; GAD, 5' primer ACATCCCCGCTTTTTCAAC and 3' primer GGA GATAGAACGGCTGGGA; SERT, 5 ' primer TGCGTTC CTTGTCCCTTATTTCA and 3 ' primer CCCGCGGG TACTCGTCACTCAG; TpH 5' primer AAGCCGACAA GACCCGAATGAAC and 3' primer TCTAAGGCGTG GCTAATGGTGTCC; VGLUT 5' primer TGGGGATA CATCGTCACTCA and 3' primer GGGAGCAATGT CAAGATGGT. An embryonic cDNA library was used to isolate amphioxus amplicons. In some cases, the amplicons 

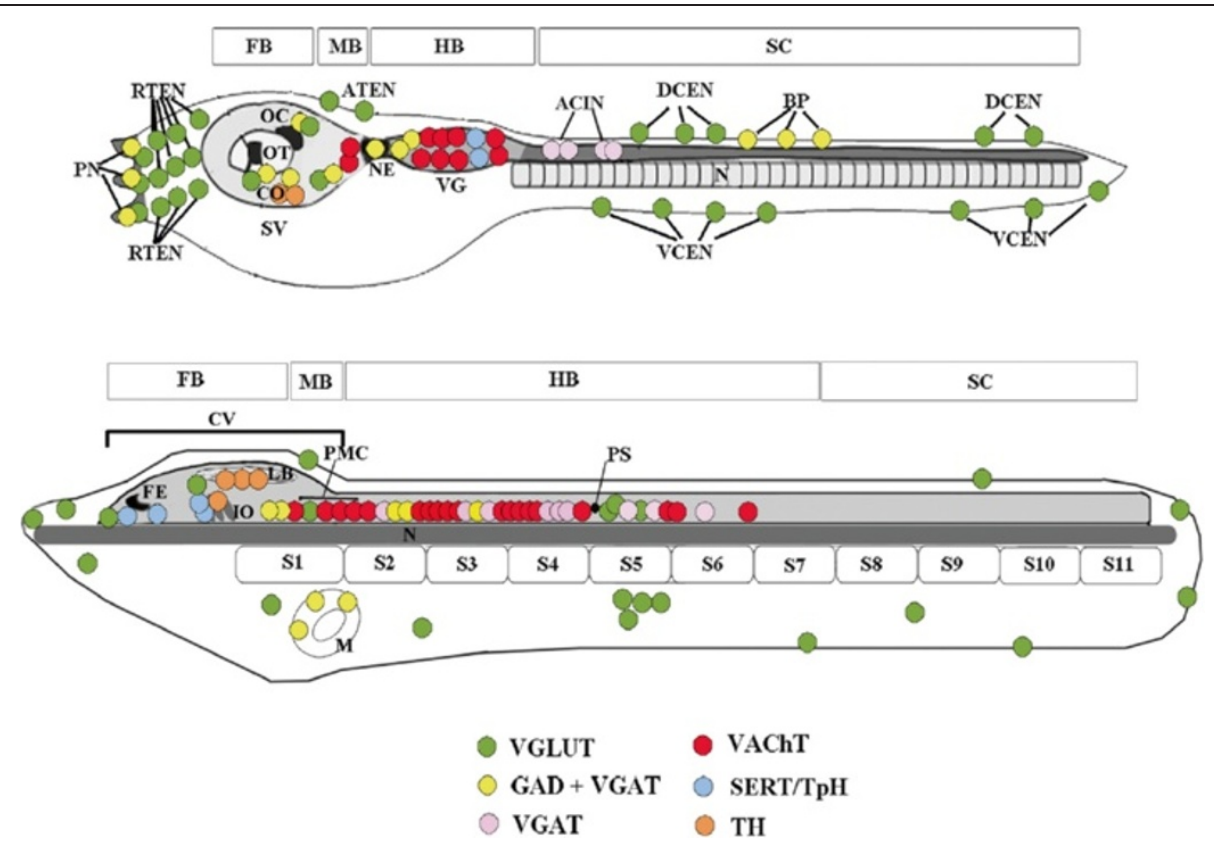

Figure 13 Schematic representation of VGLUT, GAD + VGAT, VGAT, VAChT, SERT/TpH and TH expression in the central and peripheral nervous systems of the ascidian tunicate tadpole and the amphioxus larva. For both the ascidian tunicate tadpole and the amphioxus larva the regions of the central nervous system homologous to the vertebrate forebrain (FB), midbrain (MB), hindbrain (HB) and spinal cord (SC) are indicated. The central nervous system of the ascidian tunicate tadpole larva is divided into a sensory vesicle (SV), a visceral ganglion (VG), and a caudal nerve cord [36]. A slender neck (NE) region is present between the SV and VG. The anterior part of SV contains two sensory organs: the otolith (OT), used for the perception of gravity, and the ocellus (OC), for light reception. The left side of SV contains other sensory cells named coronet cells (CO). The VG consists of at least 8 motoneurons and some interneurons, while the anterior nerve cord contains the anterior caudal inhibitory neurons (ACIN). The ascidian tunicate tadpole peripheral nervous system consists of an adhesive organ with papillar neurons (PN), ectodermal neurons in the head (RTEN, rostral trunk epidermal neurons), trunk (ATEN, apical trunk epidermal neurons) and tail (DCEN and VCEN, dorsocaudal and ventrocaudal epidermal neurons, respectively), and bipolar interneurons (BP). The CNS of an amphioxus larva includes an anterior cerebral vesicle (CV), which, anteriorly, contains a frontal eye complex (FE) and, posteriorly, the infundibular organ (IO) as well as the lamellar body (LB). The primary motor center (PMC) is located at the posterior end of the CV and thus significantly anterior to the first pigment spot (PS). S, somite; N, notochord; M, mouth.

were identified by RT-PCR on RNA samples from amphioxus adults. PCR experiments were carried out in a $50 \mu \mathrm{l}$ reaction mixture using the Hot Master mix according to the manufacturer's instructions (Eppendorf, Italy). The PCR products were directly cloned using a TOPO TA cloning kit (Invitrogen, USA) and subsequently sequenced using a 377 PerkinElmer sequencer (PerkinElmer, USA).

\section{In situ hybridization and histological analysis}

The cDNA sequences corresponding to the clones of amphioxus VGAT, GAD, SERT, TpH and VGLUT isolated by PCR were used as templates for in vitro transcription using a DIG RNA labeling kit according to the supplier's instructions (Roche, Italy). Cholinergic neurons were studied using a riboprobe against VAChT previously isolated in the laboratory [22]. In situ hybridization analysis on amphioxus embryos was carried out following the published protocol [80]. Labeled whole mount embryos were photographed using an Olympus IX71 microscope (Olympus, Italy), and subsequently counterstained with $1 \%$ Ponceau $S$ in $1 \%$ acetic acid, dehydrated in ethanol, embedded in Spurr's resin and serially sectioned at 3-4 $\mu \mathrm{m}$. Negative control experiments were performed using sense riboprobes and no specific signal was obtained.

For double in situ hybridization assays, embryos were hybridized simultaneously with two probes labeled with fluorescein and digoxigenin and developed with the appropriate antibody conjugated to alkaline phosphatase (Boehringer, Germany). Double-staining in situ hybridization was performed as previously described [22].

Confocal images (1024 X 1024 X 8 bit) were acquired on a Leica TCS SP5 AOBS confocal laser scanning microscope (Leica Microsystems, Germany). The NBT/BCIP signal was acquired with a pinhole of 2 airy units and a $633 \mathrm{~nm}$ gas laser with the detection window set to $630-640 \mathrm{~nm}$. The red fluorescence of Fast Red (Ex Max: 553 nm, Em Max: $619 \mathrm{~nm}$ ) was excited at $514 \mathrm{~nm}$ and collected with a $590 \mathrm{~nm}$ longpass filter. Serial optical sections were taken at a z-step of $0.5 \mathrm{~mm}$. The Leica Confocal Software program was used for image acquisition, storage and analysis (Leica Microsystems, Germany). 


\section{Additional files}

\section{Additional file 1: FASTA sequences of VGLUT, TpH, SERT, GAD and VGAT proteins used for the construction of the phylogenetic trees shown in Additional file 2.}

Additional file 2: Rooted phylogenetic trees of VGLUT, TpH, SERT, GAD and VGAT proteins. The results of both Maximum Likelihood (ML) and Neighbor Joining (NJ) analyses are shown. In each tree, the robustness of the phylogenetic branching patterns was assessed by bootstrap analyses in 1,000 resampling replicates. Taxonomic abbreviations are as follows: human (Homo sapiens), pig (Sus scrofa), sheep (Ovis aries), rat (Rattus norvegicus), mouse (Mus musculus), chicken (Gallus gallus), African clawed frog (Xenopus laevis), zebrafish (Danio rerio), amphioxus (Branchiostoma floridae), sea squirt (Ciona intestinalis), sea urchin (Strongylocentrotus purpuratus), sea slug (Aplysia californica), fruit fly (Drosophila melanogaster), nematode worm (Caenorhabditis elegans).

\section{Authors' contributions}

SC conceived the study. SC and LM identified amphioxus sequences, reconstructed molecular phylogenies and carried out in situ hybridization assays. SC and PR obtained the confocal images. SC, MP and MS drafted and wrote the manuscript. All authors have read and approved the final version of the manuscript. This work was supported by MIUR (PRIN 20088JEHW3001) (to SC and MP) and by funds from ANR (ANR-09-BLAN-0262-02 and ANR-11-JSV2-002-01) and CNRS (to MS). All authors read and approved the final manuscript.

\section{Acknowledgements}

The authors would like to thank Skip Pierce, John M. Lawrence, Ray Martinez and Marilyn Wetzel (Department of Biology, University of South Florida, Tampa, FL, USA) for providing laboratory space, equipment and logistic support during the amphioxus spawning season and Jim Langeland (Department of Biology, Kalamazoo College, Kalamazoo, MI, USA) for providing the cDNA library. Moreover, we are indebted to Nicholas D. Holland for critical reading of the manuscript (Scripps Institution of Oceanography, University of California San Diego, La Jolla, CA, USA)

\section{Author details}

'Dipartimento per lo Studio del Territorio e delle sue Risorse, Università $\mathrm{d}$ Genova, Viale Benedetto XV, 5, 16132 Genoa, Italy. ${ }^{2}$ Institut de Génomique Fonctionnelle de Lyon (UCBL, CNRS UMR5242, ENSL, INRA 1288), Ecole Normale Supérieure de Lyon, 46 allée d'Italie, 69364 Lyon Cedex 07, de Lyon, France.

Received: 11 October 2011 Accepted: 27 April 2012

Published: 7 June 2012

\section{References}

1. Holland ND: Early central nervous system evolution: an era of skin brains? Nat Rev Neurosci 2003, 4:617-627.

2. Holland LZ: Chordate roots of the vertebrate nervous system: expanding the molecular toolkit. Nat Rev Neurosci 2009, 10:736-746.

3. Lacalli TC: New perspectives on the evolution of protochordate sensory and locomotory systems, and the origin of brains and heads. Philos Trans R Soc Lond B Biol Sci 2001, 356:1565-1572.

4. Wada H, Saiga H, Satoh N, Holland PW: Tripartite organization of the ancestral chordate brain and the antiquity of placodes: insights from ascidian Pax-2/5/8, Hox and Otx genes. Development 1998, 125:1113-1122.

5. Wada H, Satoh N: Patterning the protochordate neural tube. Curr Opin Neurobiology 2001, 11:16-21.

6. Takahashi T, Holland PW: Amphioxus and ascidian Dmbx homeobox genes give clues to the vertebrate origins of midbrain development. Development 2004, 131:3285-3294.

7. Putnam NH: The amphioxus genome and the evolution of the chordate karyotype. Nature 2008, 453:1064-1071

8. Holland LZ: The amphioxus genome illuminates vertebrate origins and cephalochordate biology. Genome Res 2008, 18:1100-1111.

9. Guthrie DM: The physiology and structure of the nervous system of amphioxus, Branchiostoma lanceolatum. Symposia of the Zoological Society of London 1975, 36:43-80.
10. Bone Q: The central nervous system in amphioxus. J Comp Neurol 1960, 115:27-51.

11. Lacalli TC, Holland ND, West JE: Landmarks in the Anterior Central Nervous System of Amphioxus Larvae. Philos Trans R Soc Lond Biol 1994, 344:165-185.

12. Wicht $H$, Lacalli TC: The nervous system of amphioxus: structure, development, and evolutionary significance. Can J Zool 2005, 83:122-150.

13. Holland LZ, Holland ND: Chordate origins of the vertebrate central nervous system. Curr Opin Neurobiol 1999, 9:596-602.

14. Williams NA, Holland PWH: Old head on young shoulders. Nature 1996, 383:490.

15. Holland LZ, Holland ND: Expression of AmphiHox-1 and AmphiPax-1 in amphioxus embryos treated with retinoic acid: insights into evolution and patterning of the chordate nerve cord and pharynx. Development 1996, 122:1829-1838.

16. Wada H, Garcia-Fernàndez J, Holland PWH: Colinear and segmental expression of amphioxus hox genes. Dev Biol 1999, 213:131-141.

17. Schubert M, Holland ND, Laudet V, Holland LZ: A retinoic acid-Hox hierarchy controls both anterior/posterior patterning and neuronal specification in the developing central nervous system of the cephalochordate amphioxus. Dev Biol 2006, 296:190-202.

18. Holland PWH, Holland LZ, Williams NA, Holland ND: An amphioxus homeobox gene: sequence conservation, spatial expression during development and insights into vertebrate evolution. Development 1992, 116:653-661.

19. Jackman WR, Langeland JA, Kimmel CB: islet reveals segmentation in the Amphioxus hindbrain homolog. Dev Biol 2000, 220:16-26.

20. Bardet PL, Schubert M, Horard B, Holland LZ, Laudet V, Holland ND, Vanacker JM: Expression of estrogen-receptor related receptors in amphioxus and zebrafish: implications for the evolution of posterior brain segmentation at the invertebrate-to-vertebrate transition. Evol Dev 2005, 7:223-233.

21. Candiani $\mathrm{S}$, Oliveri $\mathrm{D}$, Parodi M, Castagnola P, Pestarino M: AmphiD1/ $\beta$, a dopamine $D 1 / \beta$-adrenergic receptor from the amphioxus Branchiostoma floridae: evolutionary aspects of the catecholaminergic system during development. Dev Genes Evol 2005, 215:631-638.

22. Candiani S, Lacalli TC, Parodi M, Oliveri D, Pestarino M: The cholinergic gene locus in amphioxus: molecular characterization and developmental expression patterns. Dev Dynamics 2008, 237:1399-1411.

23. Holland ND, Holland LZ: Serotonin-containing cells in the nervous system and other tissues during ontogeny of a lancelet, Branchiostoma floridae. Acta Zool 1993, 74:195-204.

24. Candiani S, Augello A, Oliveri D, Passalacqua M, Pennati R, De Bernardi F, Pestarino M: Immunocytochemical localization of serotonin in embryos, larvae and adults of the lancelet, Branchiostoma floridae. Histochem J 2001, 33:413-420.

25. Chaudhry FA, Reimer RJ, Bellocchio EE, Danbolt NC, Osen KK, Edwards RH, Storm-Mathisen J: The vesicular GABA transporter, VGAT, localizes to synaptic vesicles in sets of glycinergic as well as GABAergic neurons. J Neurosci 1998, 18:9733-9750.

26. Mazet F, Masood S, Luke GN, Holland ND, Shimeld SM: Expression of AmphiCoe, an amphioxus COE/EBF gene, in the developing central nervous system and epidermal sensory neurons. Genesis 2004, 38:58-65.

27. Kaltenbach SL, Yu JK, Holland ND: The origin and migration of the earliest-developing sensory neurons in the peripheral nervous system of amphioxus. Evol Dev 2009, 11(2):142-151.

28. Kupfermann I: Functional studies of cotransmission. Physiol Revs 1991, 71:683-732

29. Boulland JL, Qureshi T, Seal RP, Rafiki A, Gundersen V, Bergersen LH, Fremeau RT Jr, Edwards RH, Storm-Mathisen J, Chaudhry FA: Expression of the vesicular glutamate transporters during development indicates the widespread corelease of multiple neurotransmitters. J Comp Neurol 2004, 480(3):264-280.

30. Barreiro-Iglesias A, Cornide-Petronio ME, Anadón R, Rodicio MC: Serotonin and GABA are colocalized in restricted groups of neurons in the larval sea lamprey brain: insights into the early evolution of neurotransmitter colocalization in vertebrates. J Anat 2009, 215(4):435-443.

31. Uemura H, Tezuka Y, Hasegawa C, Kobayashi H: Immunohistochemical investigation of neuropeptides in the central nervous system of the amphioxus, Branchiostoma belcheri. Cell Tissue Res 1994, 277:279-287. 
32. Pestarino M, Lucaroni B: FMRFamide-like immunoreactivity in the central nervous system of the lancelet Branchiostoma lanceolatum. Isr J Zool 1996, 42:227-234.

33. Moret F, Guilland JC, Coudouel S, Rochette L, Vernier P: Distribution of tyrosine hydroxylase, dopamine, and serotonin in the central nervous system of amphioxus (Branchiostoma lanceolatum): implications for the evolution of catecholamine systems in vertebrates. J Comp Neurol 2004, 468:135-150.

34. Anadón $\mathrm{R}$, Adrio F, Rodríguez-Moldes I: Distribution of GABA immunoreactivity in the central and peripheral nervous system of amphioxus (Branchiostoma lanceolatum Pallas). J Comp Neurol 1998, 401:293-307.

35. Pascual-Anaya J, D'Aniello S: Free amino acids in the nervous system of the amphioxus Branchiostoma lanceolatum. A comparative study. Int J Biol Sci 2006, 2(2):87-92.

36. Meinertzhagen IA, Lemaire $P$, Okamura $Y$ : The neurobiology of the ascidian larva: recent developments in an ancient chordate. Annu Rev Neurosci 2004, 27:453-485.

37. Lacalli TC, Kelly SJ: Ventral neurons in the anterior nerve cord of amphioxus larvae. I. An inventory of cell types and synaptic patterns. J Morphol 2003, 257:190-211.

38. Lacalli TC: The dorsal compartment locomotory control system in amphioxus larvae. J Morphol 2002, 252:227-237.

39. Lacalli TC: Ventral neurons in the anterior nerve cord of amphioxus larvae. II. Further data on the pacemaker circuit. J Morphol 2003, 257:212-218.

40. Woolf NJ: Cholinergic systems in mammalian brain and spinal cord. Prog Neurobiol 1991, 37:475-524.

41. Lacalli TC: Frontal eye circuitry, rostral sensory pathways and brain organization in amphioxus larvae: evidence from 3D reconstructions. Phil Trans R Soc Lond B 1996, 351:243-263.

42. Lacalli TC: Sensory pathways in amphioxus larvae I. Constituent fibres of the rostral and anterodorsal nerves, their targets and evolutionary significance. Acta Zool (Stock) 2002, 83:149-166.

43. Jackson FR, Newby LM, Kulkarni SJ: Drosophila GABAergic systems: sequence and expression of glutamic acid decarboxlyase. J Neurochem 1990, 54:1068-1078.

44. McIntire S, Jorgensen EM, Horvitz HR: Genes required for GABA function in the nematode Caenorhabditis elegans. Nature 1993, 364:334-337.

45. Mueller T, Vernier P, Wullimann MF: A phylotypic stage in vertebrate brain development: GABA cell patterns in zebrafish compared with mouse. J Comp Neurol 2006, 494:620-634

46. Martyniuk CJ, Awad R, Hurley R, Finger TE, Trudeau VL: Glutamic acid decarboxylase 65, 67, and GABA-transaminase mRNA expression and total enzyme activity in the goldfish (Carassius auratus) brain. Brain Res 2007, 1147:154-166

47. Zega G, Biggiogero M, Groppelli S, Candiani S, Oliveri D, Parodi M, Pestarino M, Bernardi F, Pennati R: Developmental expression of glutamic acid decarboxylase andof $\gamma$-aminnobutyric acid type B Receptors in the ascidian Ciona intestinalis. J Comp Neurol 2008, 506:489-505.

48. Roberts A, Dale N, Ottersen OP, Storm-Mathisen J: Development and characterization of commissural interneurones in the spinal cord of Xenopus laevis embryos revealed by antibodies to glycine. Development 1988, 103(3):447-461

49. Villar-Cerviño V, Barreiro-Iglesias A, Anadón R, Rodicio MC: Development of glycine immunoreactivity in the brain of the sea lamprey: comparison with gamma-aminobutyric acid immunoreactivity. J Comp Neurol 2009, 512:747-767.

50. Villar-Cerviño V, Barreiro-lglesias A, Rodicio MC, Anadón R: D-serine is distributed in neurons in the brain of the sea lamprey. $J$ Comp Neurol 2010, 518:1688-1710.

51. Horie T, Nakagawa M, Sasakura Y, Kusakabe TG: Cell type and function of neurons in the ascidian nervous system. Dev Growth Differ 2009, 51:207-220.

52. Antzoulatos $\mathrm{EG}$, Byrne $\mathrm{JH}$ : Learning insights transmitted by glutamate. Trends Neurosci 2004, 27:555-560.

53. Collingridge GL, Lester RAJ: Excitatory amino acid receptors in the vertebrate central nervous system. Pharmacol Rev 1989, 40:143-210.

54. Fyk-Kolodziej B, Dzhagaryan A, Qin P, Pourcho RG: Immunocytochemical localization of three vesicular glutamate transporters in the cat retina. J Comp Neurol 2004, 475:518-530.

55. Panzanelli $P$, Valli $P$, Cantino D, Fasolo A: Glutamate and carnosine in the vestibular system of the frog. Brain Res 1994, 662:293-296.
56. Demêmes D, Wenthold RJ, Moniot B, Sans A: Glutamate-like immunoreactivity in the peripheral vestibular system of mammals. Hear Res 1990, 46:261-269.

57. Harper A, Blythe WR, Grossman G, Petrusz P, Prazma J, Pillsbury HC: Immunocytochemical localization of aspartate and glutamate in the peripheral vestibular system. Hear Res 1995, 86:171-182.

58. Horie T, Kusakabe T, Tsuda M: Glutamatergic networks in the Ciona intestinalis larva. J Comp Neurol 2008, 508:249-263.

59. Satoh G, Wang Y, Zhang P, Satoh N: Early development of amphioxus nervous system with special reference to segmental cell organization and putative sensory cell precursors: a study based on the expression of pan-neuronal marker gene Hu/elav. J Exp Zool 2001, 291:354-364.

60. Yasui K, Tabata S, Ueki T, Uemura M, Zhang SC: Early development of the peripheral nervous system in a lancelet species. J Comp Neurol 1998 393:415-425.

61. Candiani S, Oliveri D, Parodi M, Bertini E, Pestarino M: Expression of AmphiPOU-IV in the developing neural tube and epidermal sensory neural precursors in amphioxus supports a conserved role of class IV POU genes in the sensory cells development. Dev Genes Evol 2006 216:623-633.

62. Candiani S, Moronti L, Pennati R, De Bernardi F, Benfenati F, Pestarino M: The synapsin gene family in basal chordates: evolutionary perspectives in metazoans. BMC Evol Biol 2010, 10:32.

63. Rasmussen SL, Holland LZ, Schubert M, Beaster-Jones L, Holland ND: Amphioxus AmphiDelta: evolution of Delta protein structure, segmentation, and neurogenesis. Genesis 2007, 45:113-22.

64. Marek KW, Kurtz LM, Spitzer NC: cJun integrates calcium activity and tlx3 expression to regulate neurotransmitter specification. Nat Neurosci 2010 13:944-950.

65. Drapeau P, Saint-Amant L, Buss RR, Chong M, McDearmid JR, Brustein E: Development of the locomotor network in zebrafish. Prog Neurobiol 2002, 68:85-111.

66. Zega G, Pennati R, Fanzago A, De Bernardi F: Serotonin involvement in the metamorphosis of the hydroid Eudendrium racemosum. Int J Dev Biol 2007, 51:307-313.

67. Makrosova TG, Zaitseva OV, Smirnov RV: Monoamine- and peptidecontaining elements in the nemertine digestive tract. Zh Evol Biokhim Fiziol 2007, 43:60-68.

68. Pires A, Woollacott RM: Serotonin and dopamine have opposite effects on phototaxis in larvae of the bryozoan Bugula neritina. Biol Bull 1997, 192:399-409.

69. Csaba G: Presence in and effects of pineal indoleamines at very low level of phylogeny. Experientia 1993, 49:627-634.

70. Anctil M, Hurtubise P, Gillis MA: Tyrosine hydroxylase and dopamine-betahydroxylase immunoreactivities in the cnidarian Renilla koellikeri. Cell Tissue Res 2002, 310(1):109-117.

71. Goridis $\mathrm{C}$, Rohrer $\mathrm{H}$ : Specification of catecholaminergic and serotonergic neurons. Nat Rev Neurosci 2002, 3(7):531-541.

72. Kah O, Chambolle P: Serotonin in the brain of the goldfish, Carassius auratus. An immunocytochemical study. Cell Tissue Res 1983, 234:319-333.

73. Jacobs BL, Azmitia EC: Structure and function of the brain serotonin system. Physiol Rev 1992, 72:165-229.

74. Khan IA, Thomas P: Immunocitochemical localization of serotonin and gonadotropin-releasing hormone in the brain and pituitary gland of the Atlantic croaker Micropogonias undulates. Gen Comp Endocrinol 1993, 91:167-180

75. Oliveri D, Candiani S, Parodi M, Bertini E, Pestarino M: A serotonergic system in the brain of the Antarctic fish, Trematomus bernacchii. Polar Biol 2005, 28:366-371.

76. Wurst W, Bally-Cuif L: Neural plate patterning: upstream and downstream of the isthmic organizer. Nat Rev Neurosci 2001, 2:99-108.

77. Pennati R, Candiani S, Biggiogero M, Zega G, Groppelli S, Oliveri D, Parodi M, De Bernardi F, Pestarino M: Developmental expression of tryptophan hydroxylase gene in Ciona intestinalis. Dev Genes Evol 2007, 217:307-313.

78. Holland LZ, Kene M, Williams N, Holland ND: Sequence and embryonic expression of the amphioxus engrailed gene (AmphiEn): the metameric pattern of transcription resembles that of its segment-polarity homolog in Drosophila. Development 1997, 124:1723-1732.

79. Kozmik Z, Holland ND, Kalousova A, Paces J, Schubert M, Holland LZ: Characterization of an amphioxus paired box gene, AmphiPax2/5/8: 
developmental expression patterns in optic support cells, nephridium, thyroid-like structures and pharyngeal gill slits, but not in the midbrainhindbrain boundary region. Development 1999, 126:1295-1304.

80. Holland LZ, Holland PWH, Holland ND, Ferraris JD, Palumbi SR: Revealing homologies between body parts of distantly related animals by in situ hybridization to developmental genes: amphioxus versus vertebrates. In In Molecular Zoology: Advances, Strategies, and Protocols. New York: WileyLiss; 1996:267-282

81. JGI (Joint Genome Institute) [http://genome.jgi-psforg/]

82. Altschul SF, Gish W, Miller W, Myers EW, Lipman DJ: Basic local alignment search tool. J Mol Biol 1990, 215:403-410.

83. GenScan [http://genes.mit.edu/GENSCAN.html]

84. GenomeScan [http://genes.mit.edu/genomescan.html]

85. Higgins DG, Thompson JD, Gibson TJ: Using CLUSTAL for multiple sequence alignments. Methods Enzymol 1996, 226:383-402.

86. Tamura K, Peterson D, Peterson N, Stecher G, Nei M, Kumar S: MEGA5: Molecular Evolutionary Genetics Analysis Using Maximum Likelihood, Evolutionary Distance, and Maximum Parsimony Methods. Mol Biol Evol 2011, 28(10):2731-2739.

doi:10.1186/1471-2202-13-59

Cite this article as: Candiani et al:: A neurochemical map of the developing amphioxus nervous system. BMC Neuroscience 2012 13:59.

\section{Submit your next manuscript to BioMed Central and take full advantage of:}

- Convenient online submission

- Thorough peer review

- No space constraints or color figure charges

- Immediate publication on acceptance

- Inclusion in PubMed, CAS, Scopus and Google Scholar

- Research which is freely available for redistribution 